\title{
How Mannheimia haemolytica defeats host defence through a kiss of death mechanism
}

\author{
Laurent ZeCChInON, Thomas FetT, Daniel DeSMECHT* \\ Department of Pathology, Faculty of Veterinary Medicine, University of Liège, \\ FMV Sart-Tilman B43, 4000 Liège, Belgium
}

(Received 22 June 2004; accepted 6 October 2004)

\begin{abstract}
Mannheimia haemolytica induced pneumonias are only observed in goats, sheep and cattle. The bacterium produces several virulence factors, whose principal ones are lipopolysaccharide and leukotoxin. The latter is cytotoxic only for ruminant leukocytes, a phenomenon that is correlated with its ability to bind and interact with the ruminant $\beta 2$-integrin Lymphocyte Function-associated Antigen 1. This paper globally reviews all the information available on host-pathogen interactions underlying respiratory mannheimiosis (formerly pasteurellosis), from the stable and the Petri dish to the biochemical cascade of events triggered by the leukotoxin inside ruminant leukocytes. One conclusion can be made: the most widespread cattle respiratory disease with the most important impact on beef production worldwide, is probably due to a tiny ruminant-specific focal variation in the CD18- and/or CD11a-expressing genes.
\end{abstract}

\section{Mannheimia haemolytica / leukotoxin / $\beta 2$-integrin / ruminant}

Table of contents

1. Introduction

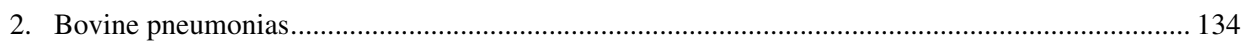

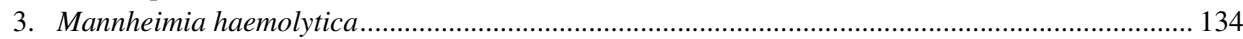

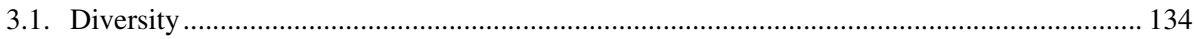

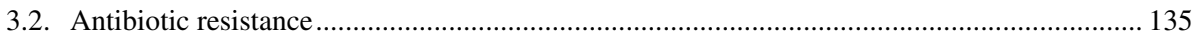

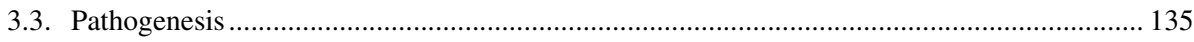

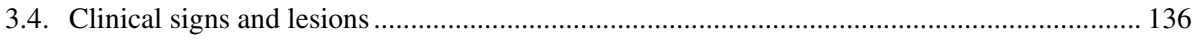

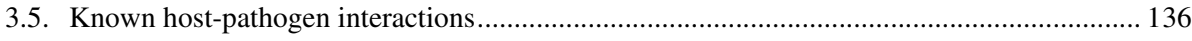

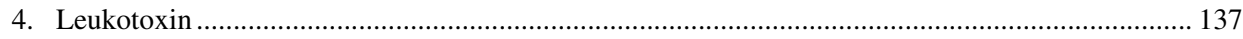

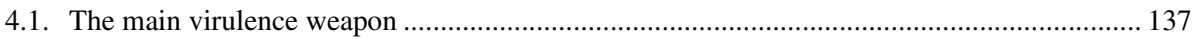

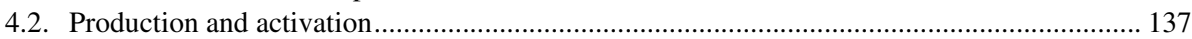

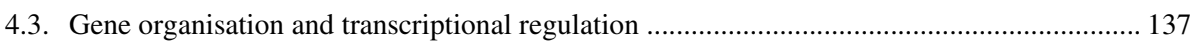

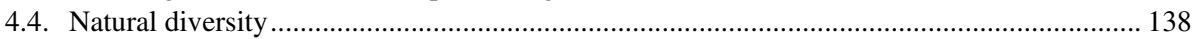

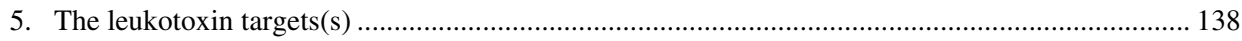

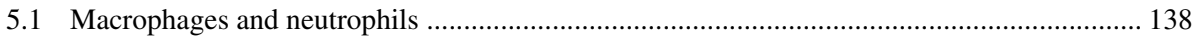

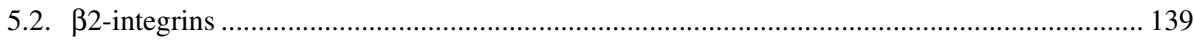

5.3. Lymphocyte Function-associated Antigen 1 .................................................................. 139

\footnotetext{
* Corresponding author: daniel.desmecht@ulg.ac.be
} 


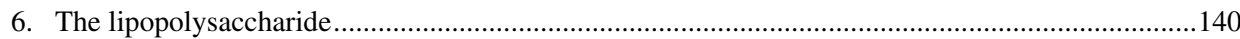

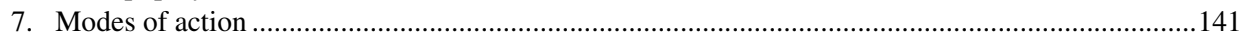

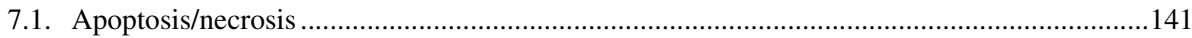

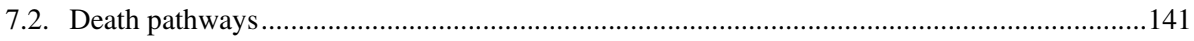

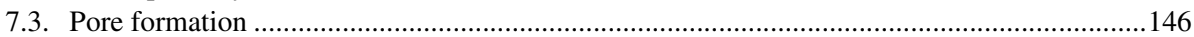

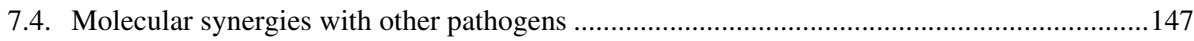

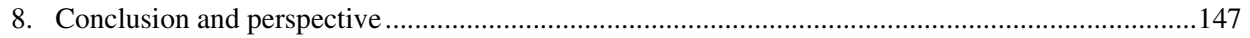

\section{INTRODUCTION}

Man understood many centuries ago that it would be more valuable to breed rather than to hunt animals like cattle, sheep and goats but he quickly realised the difficulty in warranting good animal health. Several practices such as sanitary slaughtering, quarantining animals, importing restrictions, vaccination and medical treatments have been intended to control, if not eradicate, illnesses. In the same way, antibiotics are used to fight against pathogens that have found in highly concentrated breeding conditions a choice niche extremely favourable for the contagion. Nevertheless, it is now clearly established that prophylaxy and metaphylaxy create a selective pressure towards the emergence of resistant strains which in turn could lead to new pathologies [55].

\section{BOVINE PNEUMONIAS}

The decrease of animal diseases (and bovine diseases in particular) has thus become an absolute priority since it is well-known that medical cost has the main impact on farm profitability, independently of market prices [60]. These costs are unequivocally brought by respiratory diseases $[65,119$, 157] since about $25 \%$ of the calves experience at least one episode of respiratory disease during the first year of life, with frequencies over six birth years ranging from 14 to $38 \%$. The incidence of bovine respiratory diseases is greater in male calves than in female calves during both preweaning and feedlot periods [133].
On the morbidity level, pneumonias do exert, by far, the most severe impact: they are responsible for about $75 \%$ of clinically visible diseases $[52,85]$ with average respiratory morbidity rates ranging from 15 to $45 \%$ [95].

On the mortality level, pneumonias are directly incriminated in about 45 to $55 \%$ of the cases [52, 174].

On the production costs level, medical treatments generate about eight percent of total production costs, without making an allowance for losses due to lower zootechnical performances $[65,66]$.

The main biological causes of bovine pneumonias are (i) the lungworm dictyocaulus viviparus, (ii) the viruses - the Herpes Virus-1, the Respiratory Syncytial Virus, the Parainfluenza-3 virus, the Viral DiarrheaMucosal Disease, the adenovirus, the coronavirus and (iii) the bacteria-Mannheimia haemolytica, Pasteurella multocida, Mycoplasma bovis and Arcanobacterium pyogenes [51, 86, 87, 111, 131, 189].

Most authors consider that, whatever the causative factor (environment, virus, parasite), the bacterium $M$. haemolytica is systematically found as a complicating agent. Consequently, we will further focus on this bacterium and the way it acts.

\section{MANNHEIMIA HAEMOLYTICA}

\subsection{Diversity}

Mannheimia haemolytica is a weakly hemolytic, gram-negative coccobacillus with the following complete taxonomy: superkingdom Bacteria; phylum Proteobacteria; class 
Gammaproteobacteria; order Pasteurellales; family Pasteurellaceae; genus Mannheimia [166].

The bacterium has been the subject of extensive reclassification in the past: first called Bacterium bipolare multocidum by Theodore Kitt in 1885 [96], it was renamed Pasteurella haemolytica in 1932 [135] and classified into two biotypes, A and T, based on its ability to ferment arabinose and trehalose, respectively [154]. There were $13 \mathrm{~A}$ serotypes and four $\mathrm{T}$ serotypes identified [194], the latter being reclassified as Pasteurella trehalosi in 1990 [19, 155]. Nine years later, studies based on DNA-DNA hybridisations and 16S RNA sequencing led to renaming previous A serotypes (A1, A2, A5, A6, A7, A8, A9, A12, A13, A14, A16 and A17) as Mannheimia haemolytica while the remaining A11 serotype became M. glucosida [7, 194]. The name Mannheimia was given in tribute to Walter Mannheim, a German biologist whose research has improved the understanding of the taxonomy of the Pasteurellaceae family [7].

From the twelve serotypes described, A1 and $\mathrm{A} 2$ are prevailing all over the world. A1 is known as the major causative agent of bovine mannheimiosis (formerly pasteurellosis, also known as the shipping fever), even if other serotypes like A6, A7, A9, A11 and A12 have also been reported [144] . $\mathrm{A} 1$ and $\mathrm{A} 2$ are both able to colonise the upper respiratory tract of cattle and sheep but they are often species-specific. So, healthy cattle frequently carry serotype A2 in their upper respiratory tract but following a stress or a coinfection, A1 quickly takes the place of A2 as the main serotype [58], probably by horizontal transfer from ill animals [70]. However, recent surveys have shown that serotype A6 is increasingly prevalent in the United Kingdom [49] and in the USA [3, 143] with about $30 \%$ of strains serotyped. Nevertheless, based on lipopolysaccharide profiles and outer membrane proteins within each serotype, it has been concluded that, apart from the nature of their capsules, serotypes A1 and A6 are extremely similar $[39,130]$.

\subsection{Antibiotic resistance}

Due to the often ineffective immunoprophylactic measures taken, antimicrobials are used to a large extent for prophylaxy, metaphylaxy or growth-stimulation. Moreover, the delay of analysing isolates from ill animals in a diagnostic lab makes it difficult to choose a suitable antibiotic and that is why it is commonly required to start the therapy immediately. Consequently, the result is that $M$. haemolytica exhibit increasing resistance to a large number of antimicrobial agents [177].

Besides, isolates are investigated for their antimicrobial resistance properties in the national monitoring programmes of only five European countries: France, Germany, the United Kingdom, the Netherlands and Portugal [25, 94, 118]. Data obtained from Germany and France in 1997 illustrate that there is a high degree of variability among isolates originating from the same animal source and that resistance rates may also vary over time [94].

Molecular analysis has provided insight into the variety of resistance genes so far known to be present in Mannheimia isolates. Most of these resistance genes are associated with mobile genetic elements and can thus easily be exchanged between bacteria. The occurrence of these resistance genes in a wide range of bacteria implies that Mannheimia isolates have access to large gene pools within which an interchange of resistance genes takes place [94].

The most frequent resistances are found against beta-lactams, tetracyclines, sulfonamids and aminoglycosides [76, 94, 177]. A few resistance genes have already been cloned and sequenced [70].

\subsection{Pathogenesis}

Mannheimia haemolytica plays a major role as a secondary pathogen in the final 
progression of severe pleuropneumonias in cattle, sheep and goats. Its pathogenesis involves many predisposing agents such as viruses (Parainfluenza virus 3, Bovine Herpes virus 1, Bovine Respiratory Syncytial virus), bacteria (Pasteurella multocida, Mycoplasma bovis, Arcanobacterium pyogenes), environment (excessive temperatures, change of feed, dust, ...) or stress associated to weaning, dehorning and shipping [51, 111, 189-191]. These factors seem to alter the upper respiratory tract epithelium allowing $M$. haemolytica to colonise it, escaping clearance, and to move from the nasopharynx to the lungs, leading to a broncho-alveolar kind of pneumonia which is accompanied by high morbidity $[52,85]$ and mortality $[52,174]$.

\subsection{Clinical signs and lesions}

The severity of the clinical signs can vary from unapparent to rapidly fatal disease but a few characteristic features could be mentioned: there is always some degree of depression and anorexia, fever as high as $42{ }^{\circ} \mathrm{C}$, increased heart rate, a substantial weight loss and rhinitis resulting in a mucopurulent nasal discharge or a dry, encrusted muzzle. Increased lacrymation and a cough are often present. The respiratory rate increases in the early stages, followed by dyspnea of such severity as to cause oral breathing and expiratory grunting in some cases. Auscultation reveals increased vesicular and bronchial sounds anteroventrally, progressing to rales that are at first moist but later dry; pleuritic friction rubs may be heard. Calves may stand with elbows abducted and neck extended and diarrhea occurs in some animals [189].

Pulmonary lesions are lobar, anteroventrally distributed and are characterised by extensive infiltration of neutrophils (that fail to combat infection) $[153,175]$ and exudation of fibrin into airways and alveoli. In histological descriptions, the pleura was seldom mentioned, presumably because it did not differ from expectations suggested by the gross lesions of fibrinous exudation.
The interlobular septa are distended with gelatinous material and contain edema, fibrin, leukocytes, and distended lymphatics which are frequently thrombosed. The bronchi have normal walls although there may be some necrosis and desquamation of epithelial cells. They often contain the products of deeper inflammatory processes: necrotic debris, leukocytes, fibrin, etc. [51, 189]. The cut surface usually consists of several colours due to the changes described above, plus hemorrhage, infarction, necrosis and solidification of tissue; either in the acute, fluid, congestive stages of the disease process (red hepatisation) or in the subacute stages where exudates had become more purulent (grey hepatisation) [51]. The term consolidation is used more commonly today for such exudative changes. The smaller airways are inflamed, starting at the terminal bronchioles. The alveoli contain oedema, fibrin, and occasionally haemorrhages in variable proportions, but the more interesting aspects are the inflammatory cells (neutrophils and macrophages) and the areas of coagulation necrosis. These latter are multifocal and may involve whole or confluent lobules, but not whole lobes. The necrosis importance is in fact wrought by the cytolysis of many neutrophils and macrophages that pour a variety of toxic compounds (enzymes, histamine, prostaglandins, etc.) in situ which in turn aggravate pulmonary damage [51, 189].

\subsection{Known host-pathogen interactions}

Several virulence factors have been described for M. haemolytica: they include the capsule that plays a great role in adherence and invasion, outer membrane proteins that are important in eliciting the protective immune response, adhesins implicated in colonisation, the neuraminidase that reduces the viscosity of respiratory mucus and allows closer bacterial apposition to the cell surface, the lipopolysaccharide (LPS) and the leukotoxin (LKT).

These factors allow M. haemolytica to escape or exceed clearance and host defences, 
to proliferate in the lung and to cytolyse alveolar macrophages and neutrophils, which further enhances the lung injuries [31, 91, 183].

The roles of the main actors of the illness, that is to say LKT, LPS, neutrophils and macrophages, will be further described below.

\section{LEUKOTOXIN}

\subsection{The main virulence weapon}

Leukotoxin appears to be the main virulence factor. Indeed, inactivation of $M$. haemolytica leukotoxin by a gene knockout hardly causes any further pulmonary lesions although the wild-type and mutant strains were equally capable of colonising the upper respiratory tracts of the calves [165]. Moreover, necrosis of neutrophils can be reproduced in vitro with purified LKT [5, 34, 40, 46, 88, 89, 161, 162, 176]. Biologically, it is worth noting that even if LKT is able to bind leukocytes from various animal species, it is only cytotoxic for ruminant leukocytes, suggesting that the interaction specificity between LKT and ruminant leukocytes could be responsible for the ruminant-specificity of $M$. haemolytica [92, 149, 161]. Amongst leukocytes, macrophages are more resistant than neutrophils to the lytic effect of LKT, and alveolar macrophages from adult cattle are more resistant than alveolar macrophages from calves under 16 weeks of age [137].

\subsection{Production and activation}

The leukotoxin is a $102 \mathrm{kDa}$-protein which is secreted in the logarithmic-phase of growth. It belongs to the RTX (repeats in toxin) family of multidomain exotoxins, which includes amongst others the Escherichia coli hemolysin, Actinobacillus pleuropneumoniae hemolysins, Actinobacillus actinomycetemcomitans leukotoxin, Pasteurella aerogenes Pax toxin, Bordetella pertussis adenyl cyclase hemolysin, Actinobacillus equuli hemolysin, Actinobacillus suis hemolysins and maybe a secreted protein from Haemophilus paragallinarum [16, 91, 126, 147, 180]. All these pore-forming toxins contain near the C-terminal ends of the protein highly conserved regions containing glycine-rich nonapeptide repeats, the number of which ranges from six (LKT in this case) to 41 , and seems to be related to their mechanism of activation and secretion $[32,91$, 110]. LKT is synthesised as an inactive form (proLKT) that needs acylation to become active. This process is thought to be necessary in order to remove charges from the toxin and to increase its hydrophobicity [159]. Following Westrop et al., a domain between amino acids 379 and 616 of LKT is required for recognition of the protoxin by the acylase and Lys-554 is a likely activation site [182], although it may not be the only one [140].

The study of biological effects induced by two genetically defined leukotoxin mutants has demonstrated that neither acylation nor the amino terminal 344 amino acids are required for LKT binding to the CD18 subunit of LFA-1, but are essential for LKTinduced $\left[\mathrm{Ca}^{2+}\right]_{\mathrm{i}}$ elevation, generation of reactive oxygen metabolites, production of IL-8 and cytolysis in target cells [167].

\subsection{Gene organisation and transcriptional regulation}

A four-gene polycistronic operon codes for the synthesis, the activation and the secretion of LKT: in the order of their genetic organisation, lktC is needed for LKT acylation and hence activation, lktA codes for LKT itself, and $l k t B$ and $l k t D$ code for proteins involved in secretion $[71,160]$. Two kinds of transcripts are produced, the main of which $(90 \%)$ is $\sim 3.5 \mathrm{~kb}$ long and solely encodes for $l k t C A$. Rarer transcripts span the entire four-gene cluster $(\sim 7.5 \mathrm{~kb}$ long) via antitermination within the $l k t A-$ $l k t B$ intergenic region $[73,160]$. 
The promoter region appears to be complex and LKT expression is regulated at the transcriptional level by various cis- and transacting factors $[70,72,73,116,160]$. The operon promoter activity reaches its maximum during the early logarithmic phase of bacterial growth and declines as the cells enter late logarithmic and stationary phases [54], which is well-correlated with the maximum production of LKT $[9,14,178]$. LKT is produced and secreted into the culture supernatant by all of the $M$. haemolytica strains, although some strain-to-strain variation in the amount of produced or secreted leukotoxin could be observed [40].

Bacterial growth and LKT production are co-regulated by factors such as iron, temperature [117] and oxygen. The role of $\mathrm{O}_{2}$ in the expression of LKT was studied by Uhlich et al. and it was demonstrated that FnrP, homologous to Fnr, the global transcriptional regulator of anaerobic respiration in Escherichia coli, suppresses and increases LKT transcription respectively under aerobic and anaerobic conditions $[171,172]$. Furthermore, similar results of anaerobic regulation of toxin production have been obtained with Actinobacillus actinomycetemcomitans [97]. At first sight, an increase in toxin production under anaerobic conditions seems astonishing for a respiratory pathogen. This could nevertheless appear as an evolutionary advantage since the lung lesions are anteroventrally distributed, a region which is known to be less oxygenated as the disease progresses. Thus, increasing lesions lead to less oxygenated areas; which in turn cause an increase in LKT production that amplify the disease.

\subsection{Natural diversity}

Robert Davies and his team have studied the Mannheimia haemolytica leukotoxin diversity in cattle and sheep. Sequence analysis of the $l k t A$ gene from 31 ovine and bovine strains has allowed the identification of eight main allelic variants. The substitution rates differ across the entire structural gene, suggesting a variation in the degree of selection imposed on different segments of the protein [42]. In 2002, the study of polymorphism and molecular divergence of the entire leukotoxin operon in 23 bovine and ovine isolates of M. haemolytica, six strains of Mannheimia glucosida and three of Pasteurella trehalosi has confirmed the complex mosaic structure of the operon, suggesting that it has been derived from a series of inter- and intra-species horizontal DNA transfers between distinct lineages of $M$. haemolytica. The most conserved gene seems to be $l k t D$, while $l k t A$ contains overall more substitutions than the other operon genes [43], even leading to leukotoxin diversity. For example, serotype A2 strains are associated with at least four different leukotoxin types (LktA2, LktA3, LktA8 and LktA10), whereas serotype A1, A5, A6, A8, A9 and A12 isolates are much less diverse and associated with very similar leukotoxins (LktA1.2 and LktA1.3) [40, 42]. Accordingly, Davies and Baillie have studied the effect of this amino acid diversity on leukotoxin cytotoxicity against bovine and ovine cell types [40], previously investigated on the basis of their genetic relationships [41]. Some leukotoxins associated with bovine (LktA1.1) and ovine (LktA1.2 and LktA1.3) strains differ in their cytotoxicity against the same cell type, i.e. against bovine or ovine neutrophils but overall, the leukotoxin structure and function are highly conserved in $M$. haemolytica. Therefore, the data support the hypothesis that the most likely advantage of the recombinational exchanges to the pathogen is the generation of antigenic variation which will provide an adaptative advantage against the host antibody response [40].

\section{THE LEUKOTOXIN TARGETS(S)}

\subsection{Macrophages and neutrophils}

The central role of macrophages and neutrophils in the development of fulminating pneumonic mannheimiosis is well supported. 
Experimental aerosol exposure to M. haemolytica induces rapid infiltration of neutrophils into the lung and a marked increase in the neutrophil/macrophage ratio in pulmonary lavage fluid of calves [175]. These changes correlate well with characteristic reported histologic features in which (i) small airways become plugged with purulent exudate [112] and (ii) clustered inflammatory cells with elongated or streaming nuclei, referred to as "oat cells", are commonly found within inflamed alveoli [51]. Furthermore, there is reliable evidence indicating that mobilisation of neutrophils does not effectively fight infection but contributes to the development of lung lesions; as a matter of fact, neutrophil depletion prior to inoculation with $M$. haemolytica protected calves from the development of gross fibrinopurulent pneumonic lesions [153, 179], although less severe inflammatory changes still occurred [20]. Thus, the host-pathogen interaction centrally involved is between LKT and polymorphonuclear leukocytes $(\mathrm{PMN})$ and the neutrophil-mediated inflammatory response itself appears to be a major determinant of $M$. haemolytica pathogenesis.

\section{2. $\beta 2$-integrins}

Another amazing observation has led to set a hypothesis concerning the nature of the interaction between LKT and ruminant neutrophils: LKT do not induce leukocyte cytolysis from BLAD animals, an acronym designating the genetic illness called Bovine Leukocyte Adhesion Deficiency, which is characterised by a deficit in PMN trafficking. This shortage significantly decreases, nay, abolishes their ability to self-extract from the bloodstream by diapedesis, resulting in the recurrent apparition of infectious disorders in these animals.

At the molecular level, the BLAD phenotype is due to the $\mathrm{D} 128 \mathrm{G}$ mutation in the CD18 beta subunit of $\beta 2$-integrins which results in a very important decrease of their membrane expression [151, 152]. Indeed, this family of integrins is precisely respon- sible for the leukocyte fixation at the endothelium surface - the initial step of diapedesis - through their interaction with intercellular adhesion molecules (ICAM). Therefore, the resistance exhibited by BLAD neutrophils towards LKT suggests that $\beta 2$ integrins are the ruminants Achille heel for $M$. haemolytica's LKT.

\subsection{Lymphocyte Function-associated Antigen 1}

Integrins are transmembrane receptors that play an important role in cellular adhesion even if their recognition as a surface receptor family only dates back to 1987 [81]. Since, they were extensively studied (more than 26000 articles to date) and appear to be implicated in many biological, physiological and pathological processes. All integrins consist of a 120 to $180 \mathrm{kDa}$ alpha subunit and a 90 to $110 \mathrm{kDa}$ beta subunit that are non-covalently associated singlepass transmembrane proteins [158]. The bulk of each integrin subunit is extracellular, where it typically functions as a receptor for extracellular matrix molecules or as a counterreceptor for surface proteins of apposed cells [82]. Approximately 20 integrins are described to date, which are classified into eight sub-families, named according to their beta subunit, for example $\beta 2$-integrins. CD18 is the constant beta-subunit of the $\beta 2$-integrin family. It is found associated with CD11a-d alpha-subunits, leading to the heterodimers CD11a/CD18 or LFA-1 (Lymphocyte Function-associated Antigen 1) that predominates, CD11b/CD18 or Mac-1, CD11c/CD18 or CR4 and CD11d/CD18 $[15,168]$. The CD11a-d/CD18 heterodimers are expressed on all leukocytes and mediate high affinity adhesion to a variety of cell types that express one or more of the $\beta 2$-integrin ligands, the intercellular adhesion molecules (ICAM-1 to -5) [8, 59, 129, 168].

The expression level of $\beta 2$-integrins is regulated by several factors, including mediators of inflammation, cytokines (interleukins- 1 and -4 , interferon $\alpha$ and tumour 
necrosis factor- $\beta$ ) and the formation of $\mathrm{Fc}$ g-receptor complexes. For example, phorbol myristate acetate (PMA), a mimetic of diacylglycerol that activates the protein kinase $C[50,132,136]$, increases the expression of LFA-1 from normal bovines but not from BLAD animals, because the mutant CD18 is no more able to bind any CD11. These findings indicate that the expression of CD18 by bovine neutrophils is a dynamic system, capable of rapidly responding to inflammatory stimuli by increasing surface expression of CD18 [33, 62].

In the context of the interaction between LKT and ruminant $\beta 2$-integrins, several studies have demonstrated that when bovine leukocytes are incubated with antibodies directed against CD11a or CD18, the cytotoxic effect of LKT is decreased, nay, abolished. These data suggest that the binding of LKT on ruminant LFA-1 is liable for the virulence specificity of $M$. haemolytica against ruminants. The precise identification of the subunit that binds LKT appears controversed [88], even if CD18 seems probable [5, 46, 109]. Fortunately, the recent cloning, sequencing and characterisation of the Bos taurus CD11a [56] will give the first opportunity to express homologous and heterologous LFA-1 in vitro to definitely answer the question.

\section{THE LIPOPOLYSACCHARIDE}

Bacterial lipopolysaccharides (LPS), derived from gram-negative microorganisms, typically consist of a hydrophobic domain known as lipid A (or endotoxin), a non-repeating "core" oligosaccharide and a distal polysaccharide (or O-antigen) [145].

The presence of LPS in RTX toxin preparations, as well as the harsh conditions required to remove it, suggests that LPS may complex with RTX toxins. More, concentrated culture supernatant preparations of M. haemolytica contain LKT and LPS as the most prominent components, with an LPS/LKT molar ratio around 60:1. Com- plexes result in enhanced and stabilised leukolytic activity [100, 108]. It could then be postulated that the reproduction of disease in vitro with purified LKT would not be attributed to LKT alone. This statement can be disproved since (i) purified LKT is generally preincubated with the LPS inhibitor polymyxin B and (ii) LPS could be quantified with the Limulus amebocyte lysate test.

Furthermore, a recent study has indicated an association between the incidence and severity of ovine pneumonic mannheimiosis and the LPS chemotype, suggesting an important role for the LPS chemotype in determining host-species susceptibility to lung infection [75]. Indeed, the LPS chemotype varies both between and within serotypes of M. haemolytica and is predominantly smooth in bovine isolates and rough in ovine isolates [4, 39, 98].

The LPS receptors and signal pathways in mononuclear phagocytes have been reviewed by Chen et al.; many investigators have reported that binding of LPS to many cell types is nonsaturable. Many other studies have on the other hand provided evidence for a role of receptors as potential targets in LPS stimulation [27]. For example, it is amazing to know that $\beta 2$-integrins have been described as transmembrane signalling receptors for LPS $[83,185]$. It has furthermore been concluded that CD18 molecules are not essential for cellular responses to LPS [186].

Some experiments have shown that LPS complexes with an LPS-binding acute phase protein that is rapidly synthesised in vivo following an inflammatory response. This protein, termed LPS binding protein (LBP), binds with high affinity to all chemotypes of LPS via lipid A $[169,170]$. Complexes of LPS and LBP interact with human monocytes via specific binding to the CD14 molecule [187]. It has, however, been shown that LPS can activate mononuclear phagocytes in the absence of LBP, leading to the conclusion that the CD14-dependent pathway may not be unique for LPS interaction with 
and stimulation of macrophages and monocytes.

Most types of lipid A bind a membranespanning receptor identified as toll-like receptor 4 (TLR4) present on macrophages and endothelial animal cells via an interaction that involves other proteins, including LBP, CD14 and MD-2 [2, 77, 124, 141, $148,150]$. In macrophages, lipid A activation triggers the biosynthesis of diverse mediators of inflammation such as TNF- $\alpha$ and IL-1 $\beta[17,48]$ and activates the production of costimulatory molecules required for the adaptative immune response [124, 125], events that are desirable for clearing local infections. The reader who wants to know more about LPS endotoxin is invited to read the complete review of Raetz and Whitfield [145].

Several transmembrane signalling mechanisms appear to be involved in LPS-induced activation of alveolar macrophages $[27,163$, $173,188]$. We will further describe those involved in M. haemolytica's pathogenesis.

\section{MODES OF ACTION}

\subsection{Apoptosis/necrosis}

Low and high concentrations of LKT induce respectively apoptosis and cell lysis in bovine leukocytes. The ability of low LKT concentrations to induce apoptosis in host leukocytes may allow bacteria to escape host immune surveillance by destroying the actors of innate response (macrophages and neutrophils) and enhancing the inflammatory process. At higher concentrations, the apoptotic mechanisms would be exceeded and necrosis occurs, leading to lung lesions. Nevertheless, it is not really easy to distinguish the effects caused by LKT and LPS since it is likely that they could act separately or together (when they form complexes) via common or distinct pathways that act as a complex network, transmitting many messages inside and outside the cell, controlling cell life and leading to cell lysis $[34,162]$.
Table I. Main biological effects triggered by LKT and LPS in leukocytes. LFA-1: Lymphocyte Function-associated Antigen-1; LKT: leukotoxin; LPS: lipopolysaccharide; NF- $\mathrm{KB}$ : Nuclear Factor-kappa B.

\begin{tabular}{lll}
\hline Biological effects & LKT LPS \\
\hline LFA-1 synthesis & $\bullet$ & \\
NF- $\mathrm{KB}$ activation and cytokines release & $\bullet$ & $\bullet$ \\
Intracellular calcium elevation & $\bullet$ & $\bullet$ \\
Release of arachidonic acid metabolites & $\bullet$ \\
\hline
\end{tabular}

However, activation of bovine neutrophils by $M$. haemolytica leads in bulk to elevation of intracellular calcium [139], oxidative burst [114] and production of several lipid mediators $[30,69]$ and proinflammatory cytokines [193] (Tab. I).

\subsection{Death pathways}

Upon binding to LFA-1, LKT induces tyrosine (Y735) phosphorylation of the CD18 tail via a nonreceptor tyrosine kinase (NRTK) signalling cascade involving PI3kinase and Src kinases in bovine (Figs. 1 to 4), but not in porcine leukocytes (LKT binds to porcine LFA-1 without eliciting any effects). This binding is known to involve $\mathrm{G}$ proteins $[79,90]$ and to cause, in a dose dependent way, sustained elevation in intracellular calcium in bovine leukocytes $[36,89,139]$ that results mainly from an incoming flux from the extracellular medium via voltage-gated channels (Fig. 2) $[61,79,80,139]$. This calcium entrance is clearly involved in cytolysis [61] and is essential for triggering the NF- $\mathrm{\kappa B}$ translocation into the nucleus (detectable after five minutes of exposure), as well as the production of proinflammatory cytokines such as TNF- $\alpha$, IL- $1 \beta$ and IL- 8 , since calcium chelation blocks both phenomena (Fig. 1) [80, 99, 192, 193]. It should be noted that NF-אB is known to be exploited by some pathogens [164] and that its activation and calcium elevation by LKT have only been observed 


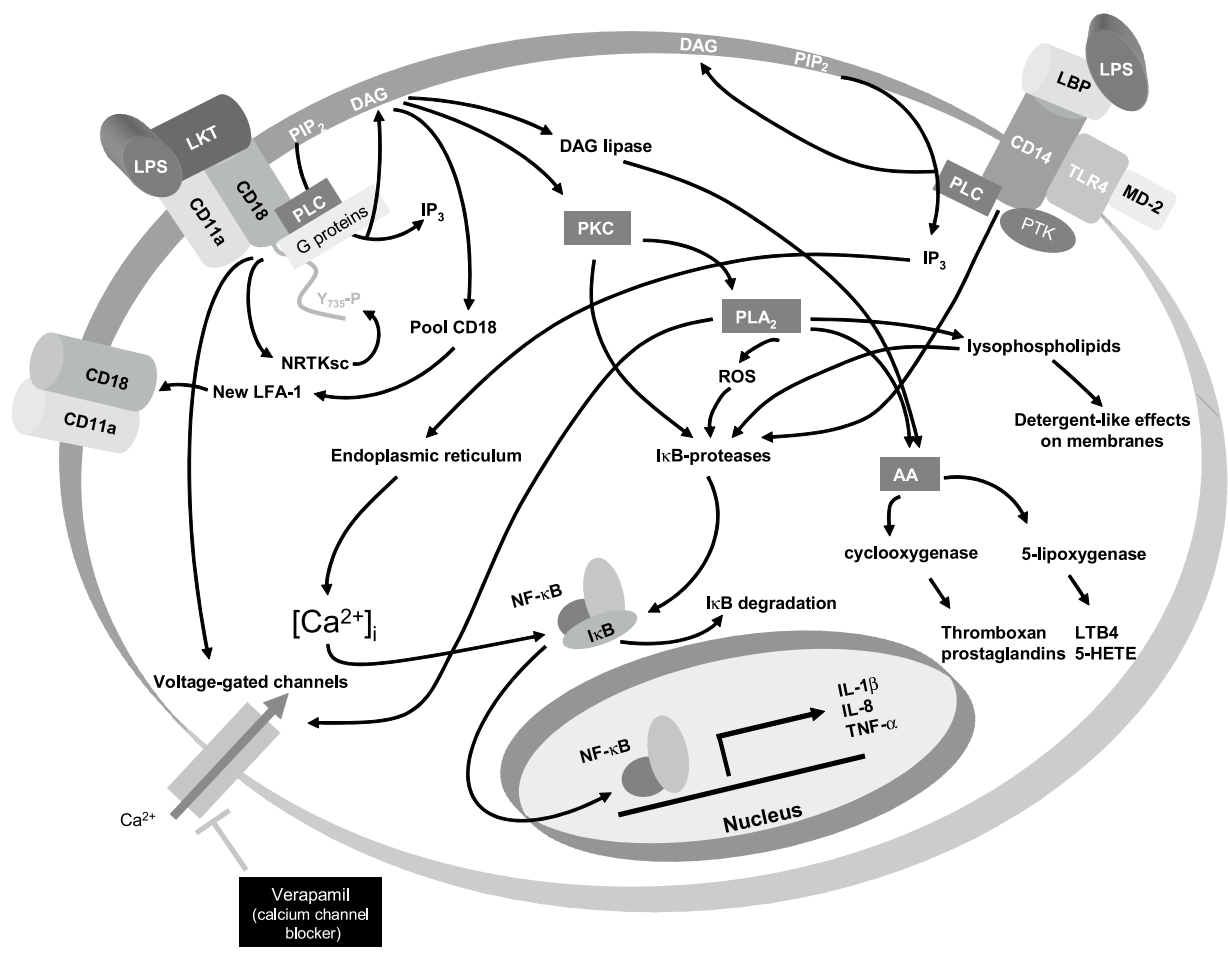

Figure 1. Leukocyte signalling pathways triggered by LKT and LPS. AA: arachidonic acid; DAG:

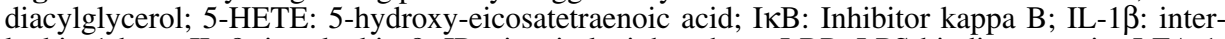
leukin-1 beta; IL-8: interleukin-8; IP $_{3}$ : inositol triphosphate; LBP: LPS binding protein; LFA-1: Lymphocyte Function-associated Antigen-1; LKT: leukotoxin; LPS: lipopolysaccharide; LTB4: leukotriene B4; NF-кB: Nuclear Factor-kappa B; NRTKsc: nonreceptor tyrosine kinase signalling cascade; $\mathrm{PIP}_{2}$ : phosphatidylinositol 4,5-bisphosphate; $\mathrm{PLA}_{2}$ : phospholipase A2; PLC: phospholipase C; PKC: protein kinase C; PTK: protein tyrosine kinase; ROS: reactive oxygen species; TNF$\alpha$ : Tumour Necrosis Factor-alpha; TLR4: toll-like receptor 4.

in bovine alveolar macrophages (BAMs) but not in porcine alveolar macrophages (PAMs) or bovine pulmonary artery endothelial cells (BPAECs), suggesting cell-type and species-specific activation mechanisms. On the other hand, LPS effects are demonstrable in BAMs, PAMs and BPAECs [80]. On the contrary to LKT, LPS induces at very low concentrations ( 1 to $10 \mathrm{ng} / \mathrm{mL}$ ) an elevation of $\left[\mathrm{Ca}^{2+}\right]_{\mathrm{i}}$ in the absence of extracellular $\mathrm{Ca}^{2+}$, suggesting a release from intracellular stores (Fig. 2). The requirement of an LPS binding protein (LBP)-CD14-cou- pled signalling mechanism involving tyrosine phosphorylation through a non Gi-Go coupled activation of PLC activation seems to be necessary, even if the role of other $\mathrm{G}$ proteins cannot be ruled out [79].

The expression of proinflammatory cytokine genes is differentially regulated by tyrosine kinase-dependent and -independent pathways in BAMs in response to LKT and LPS, since tyrosine kinase inhibitor herbimycin A blocks the expression of TNF- $\alpha$, IL- $1 \beta$ and IL- 8 genes in BAMs stimulated with LKT, while only the expression 


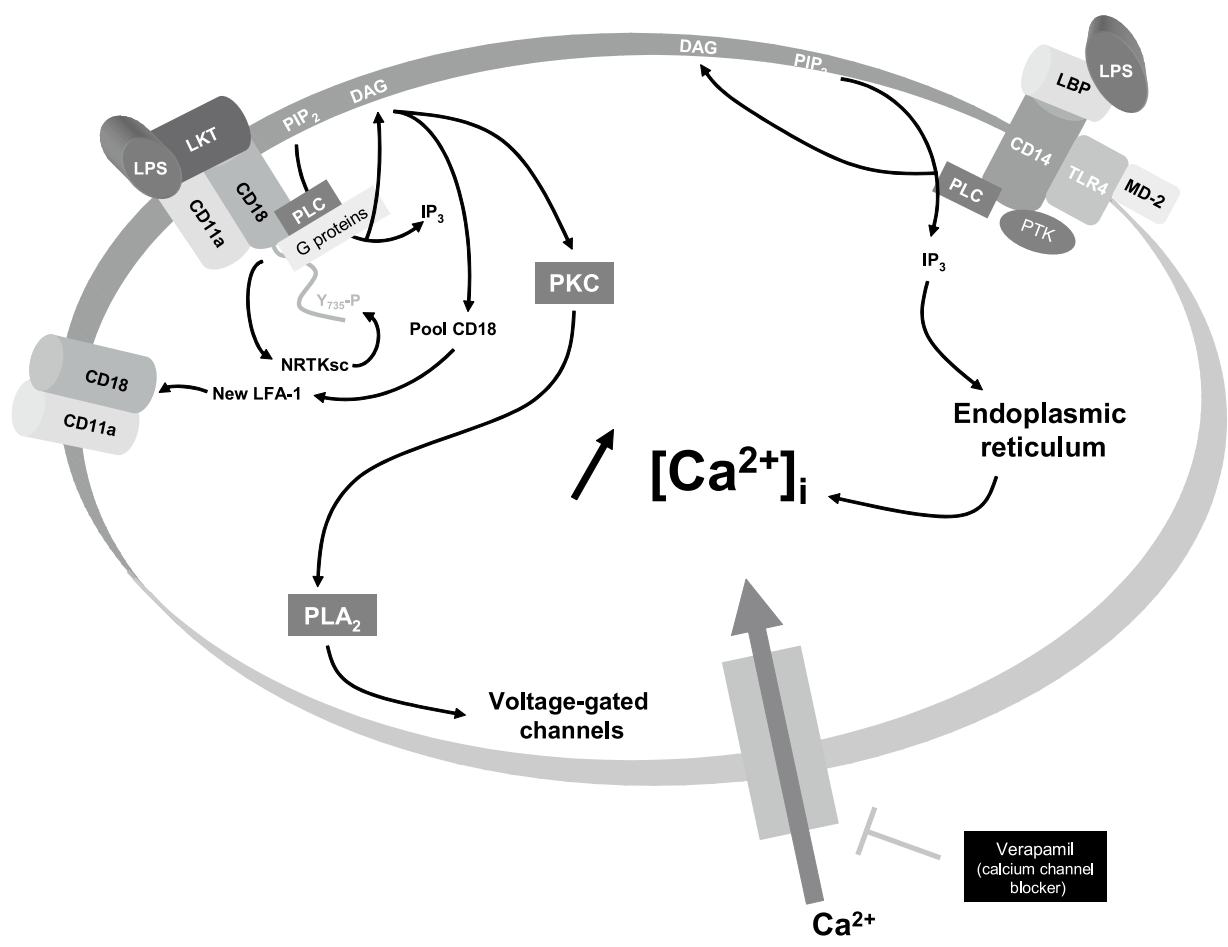

Figure 2. Leukocyte signalling pathways triggered by LKT and LPS leading to elevation of intracellular calcium. DAG: diacylglycerol; $\mathrm{IP}_{3}$ : inositol triphosphate; LBP: LPS binding protein; LFA-1: Lymphocyte Function-associated Antigen-1; LKT: leukotoxin; LPS: lipopolysaccharide; NRTKsc: nonreceptor tyrosine kinase signalling cascade; $\mathrm{PIP}_{2}$ : phosphatidylinositol 4,5-bisphosphate; $\mathrm{PLA}_{2}$ : phospholipase A2; PLC: phospholipase C; PKC: protein kinase C; PTK: protein tyrosine kinase; TLR4: toll-like receptor 4 .

of IL-1 $\beta$ is blocked in BAMs stimulated with LPS [80].

Activation of phospholipases A2 (PLA 2$)$ by LKT and C (PLC) by LKT and LPS has also been reported (Figs. 1 to 4) [64, 79, 90, 142].

$\mathrm{PLA}_{2}$ are a diverse class of enzymes with regards to function, localisation, regulation, mechanism, sequence, structure and role of divalent metal ions. They play a central role in diverse cellular processes including phospholipid digestion and metabolism, host defence, and signal transduction by catalysing the hydrolysis of the sn-2 fatty acyl bond of many different phospholipids which may themselves serve as intracellular second messengers or can be further metabolised as precursors in the production of specific proinflammatory lipid mediators such as leukotrienes, prostaglandins and hydroxyecosatetraenoic acids (HETES) via arachidonic acid (AA) formation (Fig. 4) [123]. Mammalian leukocytes contain several types of PLA $_{2}$ enzymes, the type most commonly involved in arachidonic acid production being high-molecular-mass $(85 \mathrm{kDa})$ cytosolic $\mathrm{PLA}_{2}\left(\mathrm{cPLA}_{2}\right)[10,11]$ which requires micromolar concentrations of $\mathrm{Ca}^{2+}$ for translocation from the cytosol to the nuclear 


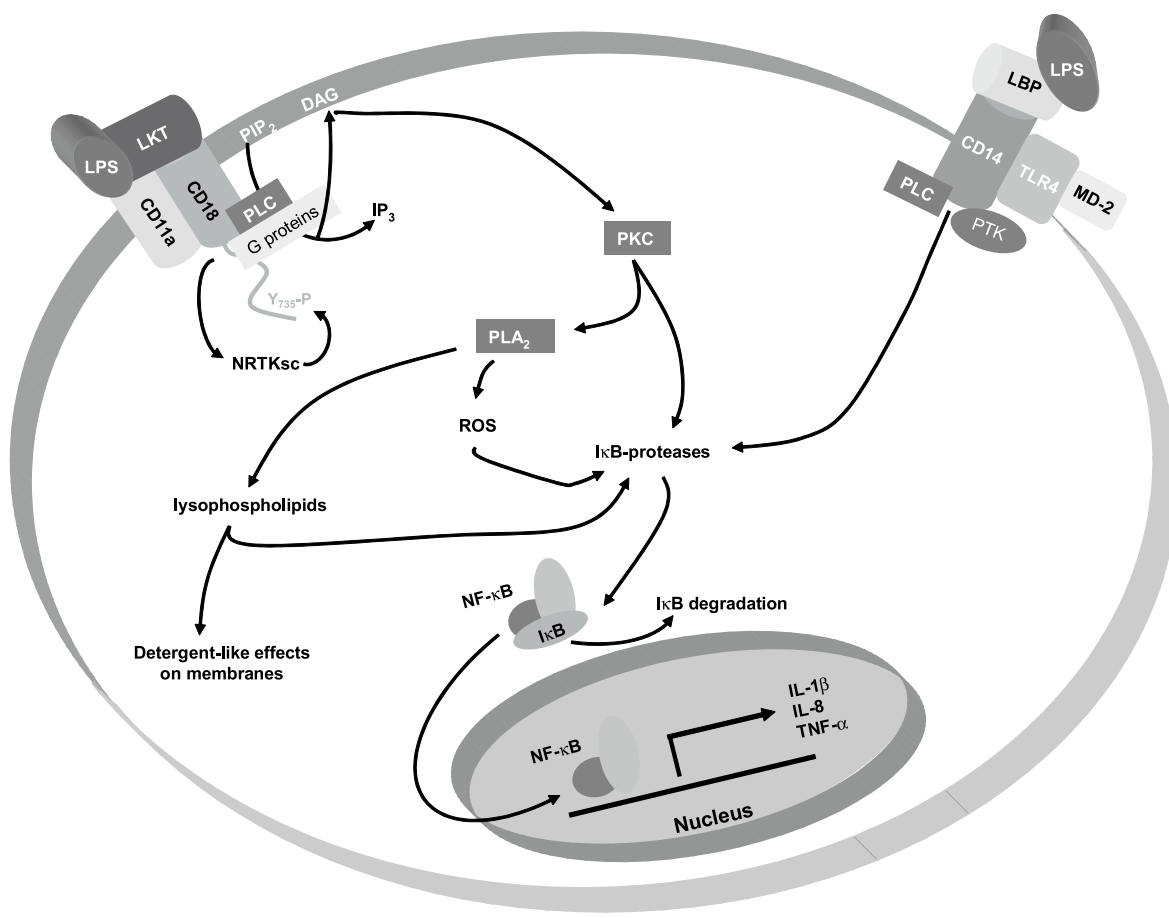

Figure 3. Leukocyte signalling pathways triggered by LKT and LPS leading to NF- $\mathrm{KB}$ activation. DAG: diacylglycerol; IאB: Inhibitor kappa B; IL-1 $\beta$ : interleukin-1 beta; IL-8: interleukin-8; IP. inositol triphosphate; LBP: LPS binding protein; LFA-1: Lymphocyte Function-associated Antigen-1; LKT: leukotoxin; LPS: lipopolysaccharide; NF-KB: Nuclear Factor-kappa B; NRTKsc: nonreceptor tyrosine kinase signalling cascade; $\mathrm{PIP}_{2}$ : phosphatidylinositol 4,5-bisphosphate; $\mathrm{PLA}_{2}$ : phospholipase A2; PLC: phospholipase C; PKC: protein kinase C; PTK: protein tyrosine kinase; ROS: reactive oxygen species; TNF- $\alpha$ : Tumour Necrosis Factor-alpha; TLR4: toll-like receptor 4.

envelope $[44,45,47,63,123]$. The $\mathrm{cPLA}_{2}$ activity seems to be regulated by $\mathrm{G}$ proteins and by protein kinase $C[79,90]$. Although $\mathrm{CPLA}_{2}$ is clearly implicated, one must also assume that other phospholipases, including $\mathrm{SPLA}_{2}$ (secretory PLA $\mathrm{PL}_{2}$ ), may also be involved in the molecular pathogenesis of M. haemolytica LKT [176].

The 5-lipoxygenase products of AA, leukotriene B4 (LTB4) and 5-hydroxy-eicosatetraenoic acid (5-HETE), are implicated (Fig. 4) as important chemotactic agents for bovine neutrophils and mediators of inflammation in M. haemolytica infection [28, 57,
68, 176]. LTB4 and 5-HETE may in fact serve as biological amplifiers in the inflammatory process by inducing a further accumulation of polymorphonuclear leukocytes $(\mathrm{PMN})$ at the site of injury $[69,120]$. Moreover, the hydrolysis of phospholipids by $\mathrm{PLA}_{2}$ leads to the elaboration of lysophospholipids, which are known to cause detergent-like effects on membranes [181] and to induce apoptosis (via NF- $\kappa \mathrm{B}$ ) as well as necrosis (Fig. 3) [78, 121, 122].

Phospholipase C-induced hydrolysis of phosphatidylinositol bisphosphate $\left(\mathrm{PIP}_{2}\right)$ releases inositol triphosphate $\left(\mathrm{IP}_{3}\right)$ and 


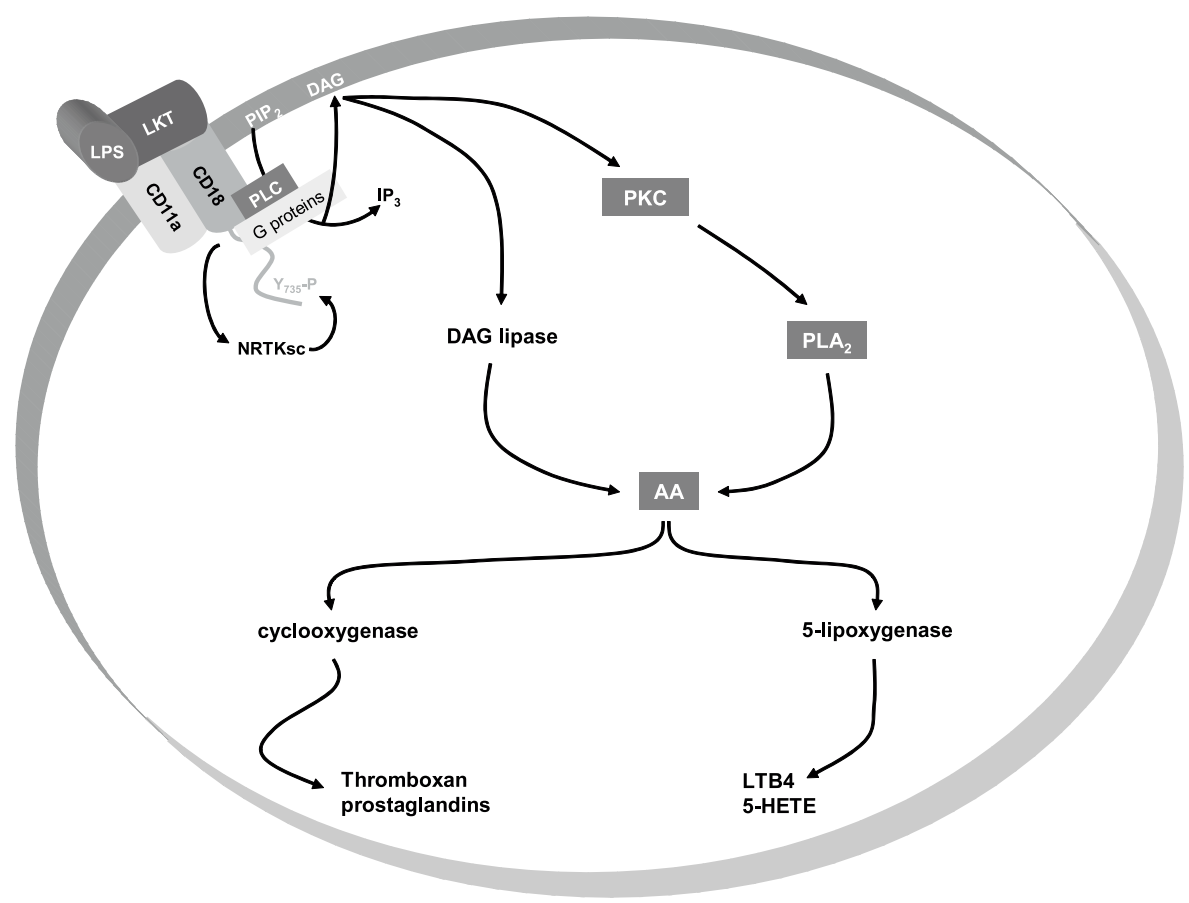

Figure 4. Leukocyte signalling pathways triggered by LKT and LPS leading to arachidonic acid metabolites. AA: arachidonic acid; DAG: diacylglycerol; 5-HETE: 5-hydroxy-eicosatetraenoic acid; $\mathrm{IP}_{3}$ : inositol triphosphate; LFA-1: Lymphocyte Function-associated Antigen-1; LKT: leukotoxin; LPS: lipopolysaccharide; LTB4: leukotriene B4; NRTKsc: nonreceptor tyrosine kinase signalling cascade; $\mathrm{PIP}_{2}$ : phosphatidylinositol 4,5-bisphosphate; $\mathrm{PLA}_{2}$ : phospholipase A2; PLC: phospholipase C; PKC: protein kinase C; TLR4: toll-like receptor 4.

diacylglycerol (DAG). It has been shown in murine and rat macrophages that $\mathrm{IP}_{3}$ mediates intracellular $\mathrm{Ca}^{2+}$ mobilisation from endoplasmic reticulum stores by LPS [107, 142]. In BAMs, this release does not involve AA [79], even if a DAG lipase pathway could convert DAG to AA [6], most probably in LKT stimulation (Fig. 4). DAG is also known to activate the protein kinase $\mathrm{C}$ (PKC) family in a variety of cell systems $[12,132,136]$. Phorbol esters, such as phorbol myristate acetate (PMA), can substitute for DAG in activating PKC [132] in a prolonged action, since phorbol esters are not readily metabolised. PMA rapidly induces $\mathrm{NF}-\kappa \mathrm{B}$ translocation into the nucleus [104] and increases the expression of LFA- 1 from bovine neutrophils, leading to enlarge the disease by increasing the number of LKT binding sites (Fig. 1) [62]. Dore et al. have shown that in PMA-non-stimulated bovine neutrophils, most PKC activity was detected in the cytosolic fraction and was dependent on the presence of added calcium and phospholipids whereas membrane-associated PKC did not have such a dependence. Stimulation with PMA caused redistribution of PKC activity in the cell consisting of a decrease in cytosolic PKC activity and an increase in membrane-associated PKC activity. As in non-stimulated cells, the former was dependent on the presence of calcium and phospholipids and the latter did not have such a requirement [50]. 
Oxygen-derived free radicals are also generated following LKT stimulation (Fig. 3) [114]. At the molecular level, they could act as second messengers and activate several factors and genes involved in the immune response and in apoptosis [35]. When overproduced, they exceed the antioxidant defence systems i.e. nonenzymatic (vita$\min \mathrm{A}, \mathrm{C}$ and $\mathrm{E}$ ) and enzymatic (superoxyde dismutase) mechanisms, which leads to oxidative stress that entail several biological effects on proteins [37, 38], DNA and lipids [21]. For its part, Mannheimia haemolytica may be able to resist at least to a certain level of free radical damage, since serotypes A1 and A2 produce superoxide dismutase $[1,146]$.

In summary (Tab. I), several factors that lead to cell lysis could be produced or activated following LKT and LPS stimulation.

\subsection{Pore formation}

LKT belongs to the RTX toxin family whose members are known to lyse their target cells through the formation of pores that lead to the efflux of $\mathrm{K}^{+}$, influx of $\mathrm{Ca}^{2+}$, colloidal osmotic swelling and eventual cell lysis. The pore size varies among bacterial species from 0.6-1 nm (LKT in this case) $[29,53,84]$ to $2-3 \mathrm{~nm}$ in diameter $[18,102]$. The LKT pore formation mechanism has not yet been described but we could approach it by analysing the way the other RTX toxins act.

Thus, the characterisation of Actinobacillus actinomycetemcomitans leukotoxin (LTX) pore formation in HL60 cells (a promyelocytic cell line) has shown that rapid cell death ensues with large conductance increases within seconds following high concentrations of toxin exposure. Cells undergo morphological changes consistent with rapid cell death [93]. When adding LTX to the bathing solution of an artificial bilayer, no channel activity was seen. However, if LTX was added to the lipid monolayer before forming the bilayer, large conductance fluctuations were seen in the bilayer. The authors interpreted this result by implying that the aqueous form of the toxin will not spontaneously incorporate into a bilayer, but if the toxin is partially unfolded, as likely happens at the lipid monolayer-water interface, insertion into the membrane occurs and channels are formed. These are also consistent with LTX being required to interact with a cell surface receptor in order to facilitate toxin activation $[93,103]$. It has been shown that this receptor is the human $\beta 2$-integrin LFA-1, expressed on immune cell surfaces matching the profile of cytolytic targets [101].

A model for the pore forming structure of the E. coli hemolysin HlyA has been proposed which assumes that the hydrophobic $\mathrm{N}$-terminal domains make up eight membrane-spanning $\alpha$-helical sequences, four of which are hydrophobic segments of 21 amino acids each and four are amphipathic with the polar side of the helices providing the hydrophilic, negatively charged interior of the pore that may explain the reported cation selectivity of the pore. The N-terminal amphiphilic portion of hemolysin does not directly participate in the pore structure but may compete with the insertion of the $\alpha$-helical amphipathic sequences assumed to be part of the pore structure and may thereby regulate the lifetime of the hemolysin pore [113]. Conflicting data on the number of toxin molecules required for pore formation have been published. However, it has been confirmed that HlyA creates a cation-selective ion channel of high conductance [13, 127, 128]. Moreover, the data suggest that a receptor is needed for the lytic activity of the toxin [13] in a two-stage process: first, the target cell binding requires glycine-rich repeat regions and modification of the toxin by the $\mathrm{C}$ gene product at an adjacent site and, afterwards, the $\mathrm{N}$-terminal hydrophobic regions allow pore formation [32]. The target cell specificity could therefore be due either to a specific binding on the receptor, to the toxin ability to interact with the membrane or even to both parameters. 
Interestingly, Ana Soloaga and her collaborators have studied the perturbation produced by purified $\alpha$-hemolysin on pure phosphatidylcholine bilayers in the form of large unilamellar vesicles, under conditions in which the toxin has been shown to induce vesicle leakage. The bilayer systems containing bound protein have been examined by differential scanning calorimetry, fluorescence spectroscopy, differential solubilisation by Triton X-114, and freeze-fracture electron microscopy. The results obtained, complemented by structure prediction studies, have led to the conclusions that (i) $\alpha$ hemolysin, under conditions leading to cell lysis, becomes inserted in the target membrane in the way of intrinsic or integral proteins and that (ii) inserted $\alpha$-hemolysin occupies only one of the membrane phospholipid monolayers, i.e. it is not a transmembrane protein. Consequently, the insertion of one or more of these molecules in the outer monolayer of the membrane could induce an increase in the lateral pressure of the monolayer lipids and, beyond a certain increase, the monolayer will reach a point of transient breakdown (perhaps repaired by a net transfer of lipids to the inner monolayer) and subsequent leakage of contents. Upon the whole, these experiments and calculations are against the idea of $E$. coli hemolysin acting as a pore-forming toxin [156].

Moreover, it is intriguing to note that the overall pore formation mechanism resembles that of other toxins of bacterial origin such as colicins, diphtheria, tetanus and botulinum toxin [127].

\subsection{Molecular synergies with other pathogens}

As already stated above, Mannheimia haemolytica's pathogenesis involves many predisposing viral and bacterial agents that could break down the antimicrobial barrier consisting of beta defensins and anionic peptides found in epithelial cells, resident and inflammatory cells, and serous and mucous secretions of the respiratory tract, then allowing Mannheimia haemolytica to be released from its usual commensal status [22].

On the other hand, impaired neutrophils and lymphocyte functions are observed in bovine viral diarrhea (BVD) virus [23], bovine respiratory syncytial (BRS) virus [184] and bovine herpes virus-1 (BHV-1) infected cattle. The latter is known to decrease host defence amongst others by diminishing the activities of T lymphocytes, B lymphocytes, monocytes and macrophages [24, 67] and by interfering with the host's antigen presentation machinery to evade the host's immune response in vivo $[74,134]$. Moreover, it has been shown that leukocyte exposure to inflammatory cytokines released in response to $\mathrm{BHV}-1$ infection (interleukin-1 beta, interleukin-8, tumour necrosis factor alpha and interferon gamma) can modulate the migration and functional activation of bovine leukocytes [26, 105, 106]. So, when Mannheimia haemolytica enters a BHV-1 infected lung, it encounters leukocytes whose recruitment and LFA-1 expression (and hence the leukotoxin susceptibility) are increased [26, 106]. In contrast, interleukin-8 expression was minimal in lesions of BRSV pneumonia [26]. Since inflammatory cytokines (tumour necrosis factor-alpha, interleukin- 1 beta and interleukin-8) are also produced in response to Mannheimia haemolytica infection [80,99, $100,192,193]$, they may, therefore, represent therapeutic targets to be modulated in order to treat or prevent mannheimiosis, as recently demonstrated in vitro [115].

\section{CONCLUSION AND PERSPECTIVE}

M. haemolytica's pneumonias are known to be one of the main diseases in the cattle industry. Several virulence factors have been described, with the most important being leukotoxin and lipopolysaccharide, that could in fact be compared to "the lips that deliver the kiss of death". They could act together (because they form complexes) 
or separately through distinct or common pathways, leading to the production of several factors that are able to damage the cell and to amplify the disease. Among these actors, $\mathrm{Ca}^{2+}$ signals play a crucial role by governing a host of vital cell functions and so are necessary for cell survival. However, more recently, it has become clear that cellular $\mathrm{Ca}^{2+}$ overload, or perturbation of intracellular $\mathrm{Ca}^{2+}$ compartimentalisation, can cause cytotoxicity and trigger either apoptotic or necrotic cell death [138].

Consequently, we can say that $M$. haemolytica could be considered among the pathogens that have reached the summum of evolution, being able to cooperate with other microbes to use the innate immune response against its host by promoting neutrophils and macrophage cell lysis. In this way, LKT seems to be very important by conferring species-specificity through specific interaction with the $\beta 2$-integrin LFA- 1 . The accurate study of this binding at the molecular level will unambiguously represent a future step in the struggle against $M$. haemolytica and could open the way to the selection of naturally resistant animals.

\section{ACKNOWLEDGMENTS}

The authors wish to thank the Belgian federal services for public health and security of the food chain and environment, grant S-6107.

\section{REFERENCES}

[1] Ackermann M.R., Brogden K.A., Response of the ruminant respiratory tract to Mannheimia (Pasteurella) haemolytica, Microbes Infect. 2 (2000) 1079-1088.

[2] Aderem A., Ulevitch R.J., Toll-like receptors in the induction of the innate immune response, Nature 406 (2000) 782-787.

[3] Al-Ghamdi G.M., Ames T.R., Baker J.C., Walker R., Chase C.C., Frank G.H., Maheswaran S.K., Serotyping of Mannheimia (Pasteurella) haemolytica isolates from the upper Midwest United States, J. Vet. Diagn. Invest. 12 (2000) 576-578.
[4] Ali Q., Davies R.L., Parton R., Coote J.G., Gibbs H.A., Lipopolysaccharide heterogeneity in Pasteurella haemolytica isolates from cattle and sheep, J. Gen. Microbiol. 138 (1992) 2185-2195.

[5] Ambagala T.C., Ambagala A.P., Srikumaran S., The leukotoxin of Pasteurella haemolytica binds to beta(2) integrins on bovine leukocytes, FEMS Microbiol. Lett. 179 (1999) $161-167$.

[6] Ambs P., Fitzke E., Dieter P., AA-release is under control of PLA2 and DAG lipase in rat liver macrophages, Adv. Prostaglandin Thromboxane Leukot. Res. 23 (1995) 81-83.

[7] Angen O., Mutters R., Caugant D.A., Olsen J.E., Bisgaard M., Taxonomic relationships of the [Pasteurella] haemolytica complex as evaluated by DNA-DNA hybridizations and 16S rRNA sequencing with proposal of Mannheimia haemolytica gen. nov., comb. nov., Mannheimia granulomatis comb. nov., Mannheimia glucosida sp. nov., Mannheimia ruminalis sp. nov. and Mannheimia varigena $\mathrm{sp}$ nov, Int. J. Syst. Bacteriol. (1999) 67-86.

[8] Bailly P., Tontti E., Hermand P., Cartron J.P., Gahmberg C.G., The red cell LW blood group protein is an intercellular adhesion molecule which binds to CD11/CD18 leukocyte integrins, Eur. J. Immunol. 25 (1995) 3316-3320.

[9] Baluyut C.S., Simonson R.R., Bemrick W.J., Maheswaran S.K., Interaction of Pasteurella haemolytica with bovine neutrophils: identification and partial characterization of a cytotoxin, Am. J. Vet. Res. 42 (1981) 1920-1926.

[10] Bauldry S.A., Wooten R.E., Leukotriene B4 and platelet activating factor production in permeabilized human neutrophils: role of cytosolic PLA2 in LTB4 and PAF generation, Biochim. Biophys. Acta 1303 (1996) 63-73.

[11] Bauldry S.A., Wooten R.E., Bass D.A., Activation of cytosolic phospholipase A2 in permeabilized human neutrophils, Biochim. Biophys. Acta 1299 (1996) 223-234

[12] Bell R.M., Burns D.J., Lipid activation of protein kinase C, J. Biol. Chem. 266 (1991) 46614664.

[13] Benz R., Schmid A., Wagner W., Goebel W., Pore formation by the Escherichia coli hemolysin: evidence for an association-dissociation equilibrium of the pore-forming aggregates, Infect. Immun. 57 (1989) 887-895.

[14] Berggren K.A., Baluyut C.S., Simonson R.R., Bemrick W.J., Maheswaran S.K., Cytotoxic effects of Pasteurella haemolytica on bovine neutrophils, Am. J. Vet. Res. 42 (1981) 13831388 
[15] Berman A.E., Kozlova N.I., Morozevich G.E., Integrins: structure and signaling, Biochemistry (Mosc) 68 (2003) 1284-1299.

[16] Berthoud H., Frey J., Kuhnert P., Characterization of Aqx and its operon: the hemolytic RTX determinant of Actinobacillus equuli, Vet. Microbiol. 87 (2002) 159-174.

[17] Beutler B., Cerami A., Tumor necrosis, cachexia, shock, and inflammation: a common mediator, Annu. Rev. Biochem. 57 (1988) 505-518.

[18] Bhakdi S., Mackman N., Nicaud J.M., Holland I.B., Escherichia coli hemolysin may damage target cell membranes by generating transmembrane pores, Infect. Immun. 52 (1986) 63-69.

[19] Bingham D.P., Moore R., Richards A.B., Comparison of DNA: DNA homology and enzymatic activity between Pasteurella haemolytica and related species, Am. J. Vet. Res. 51 (1990) 1161-1166.

[20] Breider M.A., Walker R.D., Hopkins F.M., Schultz T.W., Bowersock T.L., Pulmonary lesions induced by Pasteurella haemolytica in neutrophil sufficient and neutrophil deficient calves, Can. J. Vet. Res. 52 (1988) 205-209.

[21] Briganti S., Picardo M., Antioxidant activity, lipid peroxidation and skin diseases. What's new, J. Eur. Acad. Dermatol. Venereol. 17 (2003) 663-669.

[22] Brogden K.A., Lehmkuhl H.D., Cutlip R.C., Pasteurella haemolytica complicated respiratory infections in sheep and goats, Vet. Res. 29 (1998) 233-254.

[23] Brown G.B., Bolin S.R., Frank D.E., Roth J.A., Defective function of leukocytes from cattle persistently infected with bovine viral diarrhea virus, and the influence of recombinant cytokines, Am. J. Vet. Res. 52 (1991) 381-387.

[24] Brown T.T. Jr., Ananaba G., Effect of respiratory infections caused by bovine herpesvirus- 1 or parainfluenza- 3 virus on bovine alveolar macrophage functions, Am. J. Vet. Res. 49 (1988) 1447-1451.

[25] Caprioli A., Busani L., Martel J.L., Helmuth R., Monitoring of antibiotic resistance in bacteria of animal origin: epidemiological and microbiological methodologies, Int. J. Antimicrob. Agents 14 (2000) 295-301.

[26] Caswell J.L., Middleton D.M., Sorden S.D., Gordon J.R., Expression of the neutrophil chemoattractant interleukin-8 in the lesions of bovine pneumonic pasteurellosis, Vet. Pathol. 35 (1998) 124-131.

[27] Chen T.Y., Lei M.G., Suzuki T., Morrison D.C., Lipopolysaccharide receptors and signal transduction pathways in mononuclear phagocytes, Curr. Top. Microbiol. Immunol. 181 (1992) 169-188.

[28] Clarke C.R., Lauer A.K., Barron S.J., Wyckoff J.H. 3rd, The role of eicosanoids in the chemotactic response to Pasteurella haemolytica infection, Zentralbl. Veterinarmed. B 41 (1994) 483-491.

[29] Clinkenbeard K.D., Mosier D.A., Confer A.W., Transmembrane pore size and role of cell swelling in cytotoxicity caused by $\mathrm{Pas}$ teurella haemolytica leukotoxin, Infect. Immun. 57 (1989) 420-425.

[30] Clinkenbeard K.D., Clarke C.R., Hague C.M., Clinkenbeard P., Srikumaran S., Morton R.J., Pasteurella haemolytica leukotoxin-induced synthesis of eicosanoids by bovine neutrophils in vitro, J. Leukoc. Biol. 56 (1994) 644-649.

[31] Confer A.W., Panciera R.J., Clinkenbeard K.D., Mosier D.A., Molecular aspects of virulence of Pasteurella haemolytica, Can. J. Vet. Res. 54 (1990) S48-S52.

[32] Coote J.G., Structural and functional relationships among the RTX toxin determinants of gram-negative bacteria, FEMS Microbiol Rev. 8 (1992) 137-161.

[33] Cox E., Mast J., MacHugh N., Schwenger B., Goddeeris B.M., Expression of beta 2 integrins on blood leukocytes of cows with or without bovine leukocyte adhesion deficiency, Vet. Immunol. Immunopathol. 58 (1997) 249-263.

[34] Cudd L.A., Ownby C.L., Clarke C.R., Sun Y., Clinkenbeard K.D., Effects of Mannheimia haemolytica leukotoxin on apoptosis and oncosis of bovine neutrophils, Am. J. Vet. Res. 62 (2001) 136-141.

[35] Curtin J.F., Donovan M., Cotter T.G., Regulation and measurement of oxidative stress in apoptosis, J. Immunol. Methods 265 (2002) 49-72.

[36] Czuprynski C.J., Noel E.J., Ortiz-Carranza O., Srikumaran S., Activation of bovine neutrophils by partially purified Pasteurella haemolytica leukotoxin, Infect. Immun. 59 (1991) 3126-3133.

[37] Davies K.J., Protein damage and degradation by oxygen radicals. I. general aspects, J. Biol. Chem. 262 (1987) 9895-9901. 
[38] Davies M.J., Fu S., Wang H., Dean R.T., Stable markers of oxidant damage to proteins and their application in the study of human disease, Free Radic. Biol. Med. 27 (1999) 11511163.

[39] Davies R.L., Donachie W., Intra-specific diversity and host specificity within Pasteurella haemolytica based on variation of capsular polysaccharide, lipopolysaccharide and outer-membrane proteins, Microbiology 142 (1996) 1895-1907.

[40] Davies R.L., Baillie S., Cytotoxic activity of Mannheimia haemolytica strains in relation to diversity of the leukotoxin structural gene lktA, Vet. Microbiol. 92 (2003) 263-279.

[41] Davies R.L., Arkinsaw S., Selander R.K., Evolutionary genetics of Pasteurella haemolytica isolates recovered from cattle and sheep, Infect. Immun. 65 (1997) 3585-3593.

[42] Davies R.L., Whittam T.S., Selander R.K., Sequence diversity and molecular evolution of the leukotoxin (lktA) gene in bovine and ovine strains of Mannheimia (Pasteurella) haemolytica, J. Bacteriol. 183 (2001) 13941404.

[43] Davies R.L., Campbell S., Whittam T.S., Mosaic structure and molecular evolution of the leukotoxin operon (lktCABD) in Mannheimia (Pasteurella) haemolytica, Mannheimia glucosida, and Pasteurella trehalosi, J. Bacteriol. 184 (2002) 266-277.

[44] Dennis E.A., Diversity of group types, regulation, and function of phospholipase A2, J. Biol. Chem. 269 (1994) 13057-13060.

[45] Dennis E.A., Rhee S.G., Billah M.M., Hannun Y.A., Role of phospholipase in generating lipid second messengers in signal transduction, FASEB J. 5 (1991) 2068-2077.

[46] Deshpande M.S., Ambagala T.C., Ambagala A.P., Kehrli M.E. Jr., Srikumaran S., Bovine CD18 is necessary and sufficient to mediate Mannheimia (Pasteurella) haemolytica leukotoxin-induced cytolysis, Infect. Immun. 70 (2002) 5058-5064.

[47] Diez E., Chilton F.H., Stroup G., Mayer R.J., Winkler J.D., Fonteh A.N., Fatty acid and phospholipid selectivity of different phospholipase A2 enzymes studied by using a mammalian membrane as substrate, Biochem. J. 301 (1994) 721-726.

[48] Dinarello C.A., Interleukin-1 and interleukin-1 antagonism, Blood 77 (1991) 1627-1652.

[49] Donachie W., Bacteriology of bovine respiratory disease, UK Vet. 3 (1998) 44-46.
[50] Dore M., Neilsen N.R., Slauson D.O., Protein kinase-C activity in phorbol myristate acetatestimulated neutrophils from newborn and adult cattle, Am. J. Vet. Res. 53 (1992) 1679 1684.

[51] Dungworth D., The respiratory system, in: Jubb K., Kennedy P., Palmer N. (Eds.), Pathology of domestic animals, 4th ed., Academic Press, San Diego, 1992, pp. 589-663.

[52] Edwards A.J., Respiratory diseases of feedlot cattle in the central USA, Bovine Pract. 30 (1996) 5-7.

[53] Ehrmann I.E., Gray M.C., Gordon V.M., Gray L.S., Hewlett E.L., Hemolytic activity of adenylate cyclase toxin from Bordetella pertussis, FEBS Lett. 278 (1991) 79-83.

[54] Fedorova N.D., Highlander S.K., Generation of targeted nonpolar gene insertions and operon fusions in Pasteurella haemolytica and creation of a strain that produces and secretes inactive leukotoxin, Infect. Immun. 65 (1997) 2593-2598.

[55] Ferber D., Antibiotic resistance. Superbugs on the hoof? Science 288 (2000) 792-794.

[56] Fett T., Zecchinon L., Baise E., Desmecht D., The bovine (Bos taurus) CD11a-encoding cDNA: molecular cloning, characterisation and comparison with the human and murine glycoproteins, Gene 325 (2004) 97-101.

[57] Ford-Hutchinson A.W., Gresser M., Young R.N., 5-Lipoxygenase, Annu. Rev. Biochem. 63 (1994) 383-417.

[58] Frank G.H., Smith P.C., Prevalence of Pasteurella haemolytica in transported calves, Am. J. Vet. Res. 44 (1983) 981-985.

[59] Gahmberg C.G., Leukocyte adhesion: CD11/ CD18 integrins and intercellular adhesion molecules, Curr. Opin. Cell Biol. 9 (1997) 643-650.

[60] Gardner B.A., Northcutt S.L., Dolezal H.G., Gill D.R., Ray F.K., Morgan J.B., Shearhart C.W., Factors influencing profitability of feedlot steers, Animal Science Research Report, Oklahoma Ag Experiment Station, Oklahoma State University, Stillwater, USA, 1996, pp. 164-172.

[61] Gerbig D.G. Jr., Walker R.D., Baker J.C., Foster J.S., Moore R.N., Calcium ion involvement in the action of Pasteurella haemolytica leukotoxin, Vet. Microbiol. 19 (1989) 325335 .

[62] Gilbert R.O., Kim C.A., Yen A., Modulation, in vivo and in vitro, of surface expression of 
CD18 by bovine neutrophils, Am. J. Vet. Res. 53 (1992) 1675-1678.

[63] Glaser K.B., Mobilio D., Chang J.Y., Senko N., Phospholipase A2 enzymes: regulation and inhibition, Trends Pharmacol. Sci. 14 (1993) 92-98.

[64] Glaser K.B., Sung A., Bauer J., Weichman B.M., Regulation of eicosanoid biosynthesis in the macrophage. Involvement of protein tyrosine phosphorylation and modulation by selective protein tyrosine kinase inhibitors, Biochem. Pharmacol. 45 (1993) 711-721.

[65] Griffin D., Economic impact associated with respiratory disease in beef cattle, Vet. Clin. North Am. Food Anim. Pract. (1997) 367-377.

[66] Griffin D., Perino L., Wittum T., Feedlot respiratory disease: cost, value of preventives and intervention, Proc. Am. Assoc. Bov. Pract. (1995) 157-160.

[67] Hanon E., Lambot M., Hoornaert S., Lyaku J., Pastoret P.P., Bovine herpesvirus 1-induced apoptosis: phenotypic characterization of susceptible peripheral blood mononuclear cells, Arch. Virol. 143 (1998) 441-452.

[68] Heidel J.R., Taylor S.M., Laegreid W.W., Silflow R.M., Liggitt H.D., Leid R.W., In vivo chemotaxis of bovine neutrophils induced by 5-lipoxygenase metabolites of arachidonic and eicosapentaenoic acid, Am. J. Pathol. 134 (1989) 671-676.

[69] Henricks P.A., Binkhorst G.J., Drijver A.A., Nijkamp F.P., Pasteurella haemolytica leukotoxin enhances production of leukotriene B4 and 5-hydroxyeicosatetraenoic acid by bovine polymorphonuclear leukocytes, Infect. Immun. 60 (1992) 3238-3243.

[70] Highlander S.K., Molecular genetic analysis of virulence in Mannheimia (Pasteurella) haemolytica, Front. Biosci. 6 (2001) D1128D1150.

[71] Highlander S.K., Chidambaram M., Engler M.J., Weinstock G.M., DNA sequence of the Pasteurella haemolytica leukotoxin gene cluster, DNA 8 (1989) 15-28.

[72] Highlander S.K., Engler M.J., Weinstock G.M., Secretion and expression of the Pasteurella haemolytica Leukotoxin, J. Bacteriol. 172 (1990) 2343-2350.

[73] Highlander S.K., Wickersham E.A., Garza O., Weinstock G.M., Expression of the Pasteurella haemolytica leukotoxin is inhibited by a locus that encodes an ATP-binding cassette homolog, Infect. Immun. 61 (1993) 3942-3951.
[74] Hinkley S., Hill A.B., Srikumaran S., Bovine herpesvirus-1 infection affects the peptide transport activity in bovine cells, Virus Res. 53 (1998) 91-96.

[75] Hodgson J.C., Moon G.M., Quirie M., Donachie W., Association of LPS chemotype of Mannheimia (Pasteurella) haemolytica A1 with disease virulence in a model of ovine pneumonic pasteurellosis, J. Endotoxin Res. 9 (2003) 25-32.

[76] Hormansdorfer S., Bauer J., Resistance pattern of bovine Pasteurella, Berl. Munch. Tierarztl. Wochenschr. 109 (1996) 168-171 (in German).

[77] Hoshino K., Takeuchi O., Kawai T., Sanjo H., Ogawa T., Takeda Y., Takeda K., Akira S., Cutting edge: Toll-like receptor 4 (TLR4)deficient mice are hyporesponsive to lipopolysaccharide: evidence for TLR4 as the Lps gene product, J. Immunol. 162 (1999) 37493752 .

[78] Hsieh C.C., Yen M.H., Liu H.W., Lau Y.T., Lysophosphatidylcholine induces apoptotic and non-apoptotic death in vascular smooth muscle cells: in comparison with oxidized LDL, Atherosclerosis 151 (2000) 481-491.

[79] Hsuan S.L., Kannan M.S., Jeyaseelan S., Prakash Y.S., Sieck G.C., Maheswaran S.K., Pasteurella haemolytica A1-derived leukotoxin and endotoxin induce intracellular calcium elevation in bovine alveolar macrophages by different signaling pathways, Infect. Immun. 66 (1998) 2836-2844.

[80] Hsuan S.L., Kannan M.S., Jeyaseelan S., Prakash Y.S., Malazdrewich C., Abrahamsen M.S., Sieck G.C., Maheswaran S.K., Pasteurella haemolytica leukotoxin and endotoxin induced cytokine gene expression in bovine alveolar macrophages requires NF-kappaB activation and calcium elevation, Microb. Pathog. 26 (1999) 263-273.

[81] Hynes R.O., Integrins: a family of cell surface receptors, Cell 48 (1987) 549-554.

[82] Hynes R.O., Integrins: versatility, modulation, and signaling in cell adhesion, Cell 69 (1992) 11-25.

[83] Ingalls R.R., Golenbock D.T., CD11c/CD18, a transmembrane signaling receptor for lipopolysaccharide, J. Exp. Med. 181 (1995) 1473-1479.

[84] Iwase M., Lally E.T., Berthold P., Korchak H.M., Taichman N.S., Effects of cations and osmotic protectants on cytolytic activity of Actinobacillus actinomycetemcomitans leukotoxin, Infect. Immun. 58 (1990) 17821788. 
[85] Jensen R., Pierson R.E., Braddy P.M., Saari D.A., Lauerman L.H., England J.J., Keyvanfar H., Collier J.R., Horton D.P., McChesney A.E., Benitez A., Christie R.M., Shipping fever pneumonia in yearling feedlot cattle, $\mathrm{J}$. Am. Vet. Med. Assoc. 169 (1976) 500-506.

[86] Jericho K.W., Langford E.V., Pneumonia in calves produced with aerosols of bovine herpesvirus 1 and Pasteurella haemolytica, Can. J. Comp. Med. 42 (1978) 269-277.

[87] Jericho K.W., Yates W.D., Babiuk L.A., Bovine herpesvirus-1 vaccination against experimental bovine herpesvirus- 1 and $\mathrm{Pas}$ teurella haemolytica respiratory tract infection: onset of protection, Am. J. Vet. Res. 43 (1982) 1776-1780.

[88] Jeyaseelan S., Hsuan S.L., Kannan M.S., Walcheck B., Wang J.F., Kehrli M.E., Lally E.T., Sieck G.C., Maheswaran S.K., Lymphocyte function-associated antigen 1 is a receptor for Pasteurella haemolytica leukotoxin in bovine leukocytes, Infect. Immun. 68 (2000) 72-79.

[89] Jeyaseelan S., Kannan M.S., Briggs R.E., Thumbikat P., Maheswaran S.K., Mannheimia haemolytica leukotoxin activates a nonreceptor tyrosine kinase signaling cascade in bovine leukocytes, which induces biological effects, Infect. Immun. 69 (2001) 61316139.

[90] Jeyaseelan S., Kannan M.S., Hsuan S.L., Singh A.K., Walseth T.F., Maheswaran S.K., Pasteurella (Mannheimia) haemolytica leukotoxin-induced cytolysis of bovine leukocytes: role of arachidonic acid and its regulation, Microb. Pathog. 30 (2001) 59-69.

[91] Jeyaseelan S., Sreevatsan S., Maheswaran S.K., Role of Mannheimia haemolytica leukotoxin in the pathogenesis of bovine pneumonic pasteurellosis, Anim. Health Res. Rev. 3 (2002) 69-82.

[92] Kaehler K.L., Markham R.J., Muscoplat C.C., Johnson D.W., Evidence of species specificity in the cytocidal effects of Pasteurella haemolytica, Infect. Immun. 30 (1980) 615616.

[93] Karakelian D., Lear J.D., Lally E.T., Tanaka J.C., Characterization of Actinobacillus actinomycetemcomitans leukotoxin pore formation in HL60 cells, Biochim. Biophys. Acta 1406 (1998) 175-187.

[94] Kehrenberg C., Schulze-Tanzi G., Martel J.L., Dancla E.C., Schwarz S., Antimicrobial resistance in Pasteurella and Mannheimia: epidemiology and genetic basis, Vet. Res. 32 (2001) 323-339.
[95] Kelly A.P., Janzen E.D., A review of morbidity and mortality rates and disease occurrence in North American feedlot cattle, Can. Vet. J. (1986) 496-500.

[96] Kitt T., Uber eine experimentelle, der Rinderseuche ahnliche Infektionskranheit, Sitzunbsber. Ges. Morphol. Physiol. Muenchen (1885) 140-168.

[97] Kolodrubetz D., Phillips L., Jacobs C., Burgum A., Kraig E., Anaerobic regulation of Actinobacillus actinomycetemcomitans leukotoxin transcription is ArcA/FnrA-independent and requires a novel promoter element, Res. Microbiol. 154 (2003) 645-653.

[98] Lacroix R.P., Duncan J.R., Jenkins R.P., Leitch R.A., Perry J.A., Richards J.C., Structural and serological specificities of Pasteurella haemolytica lipopolysaccharides, Infect. Immun. 61 (1993) 170-181.

[99] Lafleur R.L., Abrahamsen M.S., Maheswaran S.K., The biphasic mRNA expression pattern of bovine interleukin-8 in Pasteurella haemolytica lipopolysaccharide-stimulated alveolar macrophages is primarily due to tumor necrosis factor alpha, Infect. Immun. 66 (1998) 4087-4092.

[100] Lafleur R.L., Malazdrewich C., Jeyaseelan S., Bleifield E., Abrahamsen M.S., Maheswaran S.K., Lipopolysaccharide enhances cytolysis and inflammatory cytokine induction in bovine alveolar macrophages exposed to Pasteurella (Mannheimia) haemolytica leukotoxin, Microb. Pathog. 30 (2001) 347357.

[101] Lally E.T., Kieba I.R., Sato A., Green C.L., Rosenbloom J., Korostoff J., Wang J.F., Shenker B.J., Ortlepp S., Robinson M.K., Billings P.C., RTX toxins recognize a beta2 integrin on the surface of human target cells, J. Biol. Chem. 272 (1997) 30463-30469.

[102] Lalonde G., McDonald T.V., Gardner P., O'Hanley P.D., Identification of a hemolysin from Actinobacillus pleuropneumoniae and characterization of its channel properties in planar phospholipid bilayers, J. Biol. Chem. 264 (1989) 13559-13564.

[103] Lear J.D., Furblur U.G., Lally E.T., Tanaka J.C., Actinobacillus actinomycetemcomitans leukotoxin forms large conductance, voltage-gated ion channels when incorporated into planar lipid bilayers, Biochim. Biophys. Acta 1238 (1995) 34-41.

[104] Legrand-Poels S., Zecchinon L., Piret B., Schoonbroodt S., Piette J., Involvement of different transduction pathways in NF-kappa $B$ activation by several inducers, Free Radic. Res. 27 (1997) 301-309. 
[105] Leite F., O’Brien S., Sylte M.J., Page T., Atapattu D., Czuprynski C.J., Inflammatory cytokines enhance the interaction of Mannheimia haemolytica leukotoxin with bovine peripheral blood neutrophils in vitro, Infect. Immun. 70 (2002) 4336-4343.

[106] Leite F., Kuckleburg C., Atapattu D., Schultz R., Czuprynski C.J., BHV-1 infection and inflammatory cytokines amplify the interaction of Mannheimia haemolytica leukotoxin with bovine peripheral blood mononuclear cells in vitro, Vet. Immunol. Immunopathol. 99 (2004) 193-202.

[107] Letari O., Nicosia S., Chiavaroli C., Vacher P., Schlegel W., Activation by bacterial lipopolysaccharide causes changes in the cytosolic free calcium concentration in single peritoneal macrophages, J. Immunol. 147 (1991) 980-983.

[108] Li J., Clinkenbeard K.D., Lipopolysaccharide complexes with Pasteurella haemolytica leukotoxin, Infect. Immun. 67 (1999) 2920-2927.

[109] Li J., Clinkenbeard K.D., Ritchey J.W., Bovine CD18 identified as a species specific receptor for Pasteurella haemolytica leukotoxin, Vet. Microbiol. 67 (1999) 91-97.

[110] Lo R.Y., Molecular characterization of cytotoxins produced by Haemophilus, Actinobacillus, Pasteurella, Can. J. Vet. Res. 54 (1990) S33-S35.

[111] Lopez A., Respiratory system, thoracic cavity and pleura, in: McGavin M., Carlton W., Zachary J. (Eds.), Thomson's Special Veterinary Pathology, 3rd ed., Mosby, SaintLouis, 2001, pp. 125-196.

[112] Lopez A., Maxie M.G., Ruhnke L., Savan M., Thomson R.G., Cellular inflammatory response in the lungs of calves exposed to bovine viral diarrhea virus, Mycoplasma bovis, and Pasteurella haemolytica, Am. J. Vet. Res. 47 (1986) 1283-1286.

[113] Ludwig A., Schmid A., Benz R., Goebel W., Mutations affecting pore formation by haemolysin from Escherichia coli, Mol. Gen. Genet. 226 (1991) 198-208.

[114] Maheswaran S.K., Weiss D.J., Kannan M.S., Townsend E.L., Reddy K.R., Whiteley L.O., Srikumaran S., Effects of Pasteurella haemolytica A1 leukotoxin on bovine neutrophils: degranulation and generation of oxygen-derived free radicals, Vet. Immunol. Immunopathol. 33 (1992) 51-68.

[115] Malazdrewich C., Thumbikat P., Abrahamsen M.S., Maheswaran S.K., Pharmacological inhibition of Mannheimia haemolytica lipopoly- saccharide and leukotoxin-induced cytokine expression in bovine alveolar macrophages, Microb. Pathog. 36 (2004) 159-169.

[116] Marciel A.M., Highlander S.K., Use of operon fusions in Mannheimia haemolytica to identify environmental and cis-acting regulators of leukotoxin transcription, Infect. Immun. 69 (2001) 6231-6239.

[117] Marciel A.M., Highlander S.K., Use of operon fusions in Mannheimia haemolytica to identify environmental and cis-acting regulators of leukotoxin transcription, Infect. Immun. 69 (2001) 6231-6239.

[118] Martel J.L., Chaslus-Dancla E., Coudert M., Poumarat F., Lafont J.P., Survey of antimicrobial resistance in bacterial isolates from diseased cattle in France, Microb. Drug Resist. 1 (1995) 273-283.

[119] Martin S.W., Meek A.H., Davis J.A., Curtis R.A., Factors associated with morbidity and mortality in feedlot cattle calves, The Bruce County Beef Project, year two, Can. J. Comp. Med. (1981) 103-112.

[120] Martin T.R., Altman L.C., Albert R.K., Henderson W.R., Leukotriene B4 production by the human alveolar macrophage: a potential mechanism for amplifying inflammation in the lung, Am. Rev. Respir. Dis. 129 (1984) 106-111.

[121] Masamune A., Sakai Y., Satoh A., Fujita M., Yoshida M., Shimosegawa T., Lysophosphatidylcholine induces apoptosis in AR42J cells, Pancreas 22 (2001) 75-83.

[122] Masamune A., Sakai Y., Yoshida M., Satoh A., Satoh K., Shimosegawa T., Lysophosphatidylcholine activates transcription factor NF-kappaB and AP-1 in AR42J cells, Dig. Dis. Sci. 46 (2001) 1871-1881.

[123] Mayer R.J., Marshall L.A., New insights on mammalian phospholipase A2(s); comparison of arachidonoyl-selective and -nonselective enzymes, FASEB J. 7 (1993) 339-348.

[124] Medzhitov R., Janeway C. Jr., Innate immunity, N. Engl. J. Med. 343 (2000) 338-344.

[125] Medzhitov R., Preston-Hurlburt P., Janeway C.A. Jr., A human homologue of the Drosophila Toll protein signals activation of adaptive immunity, Nature 388 (1997) 394397.

[126] Mena-Rojas E., Vazquez Cruz C., Vaca Pacheco S., Garcia Gonzalez O., PerezMarquez V.M., Perez-Mendez A., IbarraCaballero J., De La Garza M., Zenteno E., Negrete-Abascal E., Antigenic secreted proteins from Haemophilus paragallinarum. A 
110-kDa putative RTX protein, FEMS Microbiol. Lett. 232 (2004) 83-87.

[127] Menestrina G., Escherichia coli hemolysin permeabilizes small unilamellar vesicles loaded with calcein by a single-hit mechanism, FEBS Lett. 232 (1988) 217-220.

[128] Menestrina G., Mackman N., Holland I.B., Bhakdi S., Escherichia coli haemolysin forms voltage-dependent ion channels in lipid membranes, Biochim. Biophys. Acta 905 (1987) 109-117.

[129] Mizuno T., Yoshihara Y., Inazawa J., Kagamiyama H., Mori K., cDNA cloning and chromosomal localization of the human telencephalin and its distinctive interaction with lymphocyte function-associated antigen-1, J. Biol. Chem. 272 (1997) 1156-1163.

[130] Morton R.J., Simons K.R., Confer A.W., Major outer membrane proteins of Pasteurella haemolytica serovars 1-15: comparison of separation techniques and surfaceexposed proteins on selected serovars, Vet. Microbiol. 51 (1996) 319-330.

[131] Mosier D.A., Bacterial pneumonia, Vet. Clin. North Am. Food Anim. Pract. 13 (1997) 483-493.

[132] Mosior M., Newton A.C., Mechanism of interaction of protein kinase $\mathrm{C}$ with phorbol esters. Reversibility and nature of membrane association, J. Biol. Chem. 270 (1995) 25526-25533.

[133] Muggli-Cockett N.E., Cundiff L.V., Gregory K.E., Genetic analysis of bovine respiratory disease in beef calves during the first year of life, J. Anim. Sci. 70 (1992) 2013-2019.

[134] Nataraj C., Eidmann S., Hariharan M.J., Sur J.H., Perry G.A., Srikumaran S., Bovine herpesvirus 1 downregulates the expression of bovine MHC class I molecules, Viral Immunol. 10 (1997) 21-34.

[135] Newson I.E., Cross, F., Some bipolar organisms found in pneumonia in sheep, J. Am. Vet. Med. Assoc. 80 (1932) 711-719.

[136] Newton A.C., Protein kinase C: structure, function, and regulation, J. Biol. Chem. 270 (1995) 28495-28498.

[137] O’Brien J.K., Duffus W.P., Pasteurella haemolytica cytotoxin: relative susceptibility of bovine leucocytes, Vet. Microbiol. 13 (1987) 321-334.

[138] Orrenius S., Zhivotovsky B., Nicotera P., Regulation of cell death: the calcium-apoptosis link, Nat. Rev. Mol. Cell Biol. 4 (2003) 552-565.

[139] Ortiz-Carranza O., Czuprynski C.J., Activation of bovine neutrophils by Pasteurella haemolytica leukotoxin is calcium dependent, J. Leukoc. Biol. 52 (1992) 558-564.

[140] Pellett S., Welch R.A., Escherichia coli hemolysin mutants with altered target cell specificity, Infect. Immun. 64 (1996) 30813087.

[141] Poltorak A., He X., Smirnova I., Liu M.Y., Van Huffel C., Du X., Birdwell D., Alejos E., Silva M., Galanos C., Freudenberg M., Ricciardi-Castagnoli P., Layton B., Beutler B., Defective LPS signaling in $\mathrm{C} 3 \mathrm{H} / \mathrm{HeJ}$ and $\mathrm{C} 57 \mathrm{BL} / 10 \mathrm{ScCr}$ mice: mutations in $\mathrm{Tlr} 4$ gene, Science 282 (1998) 2085-2088.

[142] Prpic V., Weiel J.E., Somers S.D., DiGuiseppi J., Gonias S.L., Pizzo S.V., Hamilton T.A., Herman B., Adams D.O., Effects of bacterial lipopolysaccharide on the hydrolysis of phosphatidylinositol-4,5-bisphosphate in murine peritoneal macrophages, J. Immunol. 139 (1987) 526-533.

[143] Purdy C.W., Raleigh R.H., Collins J.K., Watts J.L., Straus D.C., Serotyping and enzyme characterization of Pasteurella haemolytica and Pasteurella multocida isolates recovered from pneumonic lungs of stressed feeder calves, Curr. Microbiol. 34 (1997) 244-249.

[144] Quirie M., Donachie W., Gilmour N.J., Serotypes of Pasteurella haemolytica from cattle, Vet. Rec. 119 (1986) 93-94.

[145] Raetz C.R., Whitfield C., Lipopolysaccharide endotoxins, Annu. Rev. Biochem. 71 (2002) 635-700.

[146] Rowe H.A., Knox D.P., Poxton I.R., Donachie W., Divergent activity and function of superoxide dismutases in Pasteurella haemolytica serotypes A1 and A2 and Pasteurella trehalosi serotype T10, FEMS Microbiol. Lett. 150 (1997) 197-202.

[147] Schaller A., Kuhnert P., de la PuenteRedondo V.A., Nicolet J., Frey J., Apx toxins in Pasteurellaceae species from animals, Vet. Microbiol. 74 (2000) 365-376.

[148] Schumann R.R., Leong S.R., Flaggs G.W., Gray P.W., Wright S.D., Mathison J.C., Tobias P.S., Ulevitch R.J., Structure and function of lipopolysaccharide binding protein, Science 249 (1990) 1429-1431.

[149] Shewen P.E., Wilkie B.N., Cytotoxin of Pasteurella haemolytica acting on bovine leukocytes, Infect. Immun. 35 (1982) 91-94.

[150] Shimazu R., Akashi S., Ogata H., Nagai Y., Fukudome K., Miyake K., Kimoto M., MD-2, a molecule that confers lipopolysaccharide responsiveness on Toll-like receptor 4, J. Exp. Med. 189 (1999) 1777-1782. 
[151] Shuster D.E., Bosworth B.T., Kehrli M.E. Jr., Sequence of the bovine CD18-encoding cDNA: comparison with the human and murine glycoproteins, Gene 114 (1992) $267-$ 271.

[152] Shuster D.E., Kehrli M.E. Jr., Ackermann M.R., Gilbert R.O., Identification and prevalence of a genetic defect that causes leukocyte adhesion deficiency in Holstein cattle, Proc. Natl. Acad. Sci. USA 89 (1992) 92259229.

[153] Slocombe R.F., Malark J., Ingersoll R., Derksen F.J., Robinson N.E., Importance of neutrophils in the pathogenesis of acute pneumonic pasteurellosis in calves, Am. J. Vet. Res. 46 (1985) 2253-2258.

[154] Smith G.R., The characteristics of two types of Pasteurella haemolytica associated with different pathological conditions of sheep, J. Pathol. Bacteriol. 81 (1961) 431-440.

[155] Sneath P.H., Stevens M., Actinobacillus rossii sp. nov., Actinobacillus seminis sp. nov., nom. rev., Pasteurella bettii sp. nov., Pasteurella lymphangitidis sp. nov., Pasteurella mairi sp. nov., and Pasteurella trehalosi $\mathrm{sp}$. nov, Int. J. Syst. Bacteriol. 40 (1990) 148153.

[156] Soloaga A., Veiga M.P., Garcia-Segura L.M., Ostolaza H., Brasseur R., Goni F.M., Insertion of Escherichia coli alpha-haemolysin in lipid bilayers as a non-transmembrane integral protein: prediction and experiment, Mol. Microbiol. 31 (1999) 1013-1024.

[157] Speer N.C., Young C., Roeber D., The importance of preventing bovine respiratory disease: a beef industry review, Bovine Pract. 35 (2001) 189-196.

[158] Springer T.A., Adhesion receptors of the immune system, Nature 346 (1990) 425434.

[159] Stanley P., Koronakis V., Hughes C., Acylation of Escherichia coli hemolysin: a unique protein lipidation mechanism underlying toxin function, Microbiol. Mol. Biol. Rev. 62 (1998) 309-333.

[160] Strathdee C.A., Lo R.Y., Regulation of expression of the Pasteurella haemolytica leukotoxin determinant, J. Bacteriol. 171 (1989) 5955-5962.

[161] Sun Y., Clinkenbeard K.D., Cudd L.A., Clarke C.R., Clinkenbeard P.A., Correlation of Pasteurella haemolytica leukotoxin binding with susceptibility to intoxication of lymphoid cells from various species, Infect. Immun. 67 (1999) 6264-6269.

[162] Sun Y., Clinkenbeard K.D., Ownby C.L., Cudd L., Clarke C.R., Highlander S.K.,
Ultrastructural characterization of apoptosis in bovine lymphocytes exposed to Pasteurella haemolytica leukotoxin, Am. J. Vet. Res. 61 (2000) 51-56.

[163] Sweet M.J., Hume D.A., Endotoxin signal transduction in macrophages, J. Leukoc. Biol. 60 (1996) 8-26.

[164] Tato C.M., Hunter C.A., Host-pathogen interactions: subversion and utilization of the NF-kappa B pathway during infection, Infect. Immun. 70 (2002) 3311-3317.

[165] Tatum F.M., Briggs R.E., Sreevatsan S.S., Zehr E.S., Ling Hsuan S., Whiteley L.O., Ames T.R., Maheswaran S.K., Construction of an isogenic leukotoxin deletion mutant of Pasteurella haemolytica serotype 1: characterization and virulence, Microb. Pathog. 24 (1998) 37-46.

[166] The NCBI taxonomy browser [on line], http://www.ncbi.nlm.nih.gov/Taxonomy/ Browser/wwwtax.cgi [consulted 31 August 2004].

[167] Thumbikat P., Briggs R.E., Kannan M.S., Maheswaran S.K., Biological effects of two genetically defined leukotoxin mutants of Mannheimia haemolytica, Microb. Pathog. 34 (2003) 217-226.

[168] Tian L., Yoshihara Y., Mizuno T., Mori K., Gahmberg C.G., The neuronal glycoprotein telencephalin is a cellular ligand for the CD11a/CD18 leukocyte integrin, J. Immunol. 158 (1997) 928-936.

[169] Tobias P.S., Soldau K., Ulevitch R.J., Isolation of a lipopolysaccharide-binding acute phase reactant from rabbit serum, J. Exp. Med. 164 (1986) 777-793.

[170] Tobias P.S., Soldau K., Ulevitch R.J., Identification of a lipid A binding site in the acute phase reactant lipopolysaccharide binding protein, J. Biol. Chem. 264 (1989) 1086710871.

[171] Uhlich G.A., McNamara P.J., Iandolo J.J., Mosier D.A., Cloning and characterization of the gene encoding Pasteurella haemolytica FnrP, a regulator of the Escherichia coli silent hemolysin sheA, J. Bacteriol. 181 (1999) 3845-3848.

[172] Uhlich G.A., McNamara P.J., Iandolo J.J., Mosier D.A., FnrP interactions with the Pasteurella haemolytica leukotoxin promoter, FEMS Microbiol. Lett. 186 (2000) 73-77.

[173] Ulevitch R.J., Tobias P.S., Receptor-dependent mechanisms of cell stimulation by bacterial endotoxin, Annu. Rev. Immunol. 13 (1995) 437-457. 
[174] Vogel J.G., Parrott C., Mortality survey in feedyards: the incidence of death from digestive, respiratory and other causes in feedyards on the Great plains, Comp. Cont. Ed. Prac. Vet. (1994) 227-234.

[175] Walker R.D., Hopkins F.M., Schultz T.W., McCracken M.D., Moore R.N., Changes in leukocyte populations in pulmonary lavage fluids of calves after inhalation of Pasteurella haemolytica, Am. J. Vet. Res. 46 (1985) 2429-2433.

[176] Wang Z., Clarke C., Clinkenbeard K., Pasteurella haemolytica leukotoxin-induced increase in phospholipase A2 activity in bovine neutrophils, Infect. Immun. 66 (1998) 1885-1890.

[177] Watts J.L., Yancey R.J. Jr., Salmon S.A., Case C.A., A 4-year survey of antimicrobial susceptibility trends for isolates from cattle with bovine respiratory disease in North America, J. Clin. Microbiol. 32 (1994) 725731.

[178] Waurzyniak B.J., Clinkenbeard K.D., Confer A.W., Srikumaran S., Enhancement of Pasteurella haemolytica leukotoxic activity by bovine serum albumin, Am. J. Vet. Res. 55 (1994) 1267-1274.

[179] Weiss D.J., Bauer M.C., Whiteley L.O., Maheswaran S.K., Ames T.R., Changes in blood and bronchoalveolar lavage fluid components in calves with experimentally induced pneumonic pasteurellosis, Am. J. Vet. Res. 52 (1991) 337-344.

[180] Welch R.A., RTX toxin structure and function: a story of numerous anomalies and few analogies in toxin biology, Curr. Top. Microbiol. Immunol. 257 (2001) 85-111.

[181] Weltzien H.U., Cytolytic and membraneperturbing properties of lysophosphatidylcholine, Biochim. Biophys. Acta 559 (1979) 259-287.

[182] Westrop G., Hormozi K., da Costa N., Parton R., Coote J., Structure-function studies of the adenylate cyclase toxin of Bordetella pertussis and the leukotoxin of Pasteurella haemolytica by heterologous $\mathrm{C}$ protein activation and construction of hybrid proteins, J. Bacteriol. 179 (1997) 871-879.

[183] Whiteley L.O., Maheswaran S.K., Weiss D.J., Ames T.R., Kannan M.S., Pasteurella haemolytica $\mathrm{A} 1$ and bovine respiratory disease: pathogenesis, J. Vet. Intern. Med. 6 (1992) 11-22.

[184] Woldehiwet Z., Sharma R., Evidence of immunosuppression by bovine respiratory syncytial virus, Scand. J. Immunol. 11 (1992) 75-80.

[185] Wright S.D., Jong M.T., Adhesion-promoting receptors on human macrophages recognize Escherichia coli by binding to lipopolysaccharide, J. Exp. Med. 164 (1986) 18761888.

[186] Wright S.D., Detmers P.A., Aida Y., Adamowski R., Anderson D.C., Chad Z., Kabbash L.G., Pabst M.J., CD18-deficient cells respond to lipopolysaccharide in vitro, J. Immunol. 144 (1990) 2566-2571.

[187] Wright S.D., Ramos R.A., Tobias P.S., Ulevitch R.J., Mathison J.C., CD14, a receptor for complexes of lipopolysaccharide (LPS) and LPS binding protein, Science 249 (1990) 1431-1433.

[188] Yasui K., Becker E.L., Sha'afi R.I., Lipopolysaccharide and serum cause the translocation of G-protein to the membrane and prime neutrophils via CD14, Biochem. Biophys. Res. Commun. 183 (1992) 1280-1286.

[189] Yates W.D., A review of infectious bovine rhinotracheitis, shipping fever pneumonia and viral-bacterial synergism in respiratory disease of cattle, Can. J. Comp. Med. 46 (1982) 225-263.

[190] Yates W.D., Jericho K.W., Doige C.E., Effect of bacterial dose on pneumonia induced by aerosol exposure of calves to bovine herpesvirus-1 and Pasteurella haemolytica, Am. J. Vet. Res. 44 (1983) 238 243.

[191] Yates W.D., Jericho K.W., Doige C.E., Effect of viral dose on experimental pneumonia caused by aerosol exposure of calves to bovine herpesvirus 1 and Pasteurella haemolytica, Can. J. Comp. Med. 47 (1983) 57-63.

[192] Yoo H.S., Maheswaran S.K., Lin G., Townsend E.L., Ames T.R., Induction of inflammatory cytokines in bovine alveolar macrophages following stimulation with Pasteurella haemolytica lipopolysaccharide, Infect. Immun. 63 (1995) 381-388.

[193] Yoo H.S., Rajagopal B.S., Maheswaran S.K., Ames T.R., Purified Pasteurella haemolytica leukotoxin induces expression of inflammatory cytokines from bovine alveolar macrophages, Microb. Pathog. 18 (1995) 237252.

[194] Younan M., Fodor L., Characterization of a new Pasteurella haemolytica serotype (A17), Res. Vet. Sci. 58 (1995) 98. 